\title{
Qualidade microbiológica de polpa de frutas no Brasil: Um panorama dos anos 2010
}

\section{a 2020}

\author{
Microbiological quality of fruit pulp in Brazil: An overview of the years 2010 through 2020 \\ Calidad microbiológica de pulpa de frutas en Brasil: Un panorama de los años 2010 hasta 2020
}

Recebido: 21/05/2021 | Revisado: 29/05/2021 | Aceito: 02/06/2021 | Publicado: 18/06/2021

\author{
Juliana de Oliveira Moraes \\ ORCID: https://orcid.org/0000-0002-6366-5400 \\ Instituto Federal de Educação, Ciência e Tecnologia de Alagoas, Brasil \\ E-mail: juliana.moraes@ifal.edu.br \\ Mirian Ribeiro Galvão Machado \\ ORCID: https://orcid.org/0000-0001-7505-7659 \\ Universidade Federal de Pelotas, Brasil \\ E-mail:mgalvao@ufpel.edu.br
}

\begin{abstract}
Resumo
Esta revisão traz uma visão geral acerca da qualidade microbiológica de polpas de frutas comercializadas no Brasil, através de uma revisão integrativa de estudos publicados entre os anos de 2010 e 2020 . Foram consultadas três bases de dados (Google acadêmico, Scientific Electronic Library Online e Biblioteca Virtual da Saúde), usando-se os termos descritores: polpa de frutas, qualidade, qualidade microbiológica e qualidade higiênico-sanitária. Os resultados das buscas foram avaliados e selecionados, considerando o objetivo do estudo, assim como os fatores de inclusão e exclusão. Foram selecionados 56 estudos para análise, descrição, discussão e síntese do conhecimento produzido através dos mesmos. Após análise, verificou-se que 94,6\% dos estudos foram publicados no idioma português e 44,6\% foram realizados no Nordeste do Brasil. Em geral, as análises microbiológicas foram realizadas através de métodos convencionais $(87,5 \%)$ e os parâmetros mais avaliados foram: enumeração de coliformes termotolerantes (71,4\%), pesquisa de Salmonella sp. (64,3\%), enumeração de bolores e leveduras $(60,7 \%)$ e enumeração de coliformes totais $(58,9 \%)$. Os estudos que realizaram a enumeração de coliformes termotolerantes, enumeração de bolores e leveduras e pesquisa de Salmonella sp., 31,7\%, 67,7\% e 16,7\%, respectivamente, apresentaram pelo menos uma amostra em desacordo com os limites permitidos pela legislação brasileira. Os resultados dos estudos avaliados demonstraram que o processamento de polpas de frutas no Brasil ainda enfrenta problemas de padronização acerca dos parâmetros microbiológicos exigidos e limites considerados seguros para comercialização deste produto. Neste contexto, destacam-se a necessidade de maior vigilância e inspeção do processamento de polpas de frutas comercializadas no território brasileiro.
\end{abstract}

Palavras-chave: Frutas processadas; Legislação; Microbiologia.

\begin{abstract}
This review provides an overview of the microbiological quality of fruit pulps marketed in Brazil, through an integrative review of studies published between the years 2010 and 2020. Three databases were consulted (Academic Google, Scientific Electronic Library Online and Biblioteca Virtual Health), using the descriptors: fruit pulp, quality, microbiological quality and hygienic-sanitary quality. The search results were evaluated and selected, considering the objective of the study, as well as the inclusion and exclusion factors. The total of the 56 studies were selected for analysis, description, discussion and synthesis of the knowledge produced through them. After analysis, it was found that $94.6 \%$ of the studies were published in portuguese and $44.6 \%$ carried out in Northeast Brazil. In general, microbiological analyzes were performed using conventional methods $(87.5 \%)$ and the most evaluated parameters were enumeration of thermotolerant coliforms (71.4\%), research by Salmonella sp. (64.3\%), enumeration of molds and yeasts $(60.7 \%)$ and enumeration of total coliforms $(58.9 \%)$. The studies that carried out the enumeration of thermotolerant coliforms, enumeration of molds and yeasts and research of Salmonella sp., 31.7\%, 67.7\% and 16.7\%, respectively, presented at least one sample in disagreement with the permitted limits Brazilian law. The results of the evaluated studies demonstrated that the processing of fruit pulps in Brazil still faces problems of standardization regarding the required microbiological standards and limits considered safe for commercialization of this product. In this context, the need for greater vigilance and inspection of the processing of fruit pulps commercialized in the Brazilian territory is highlighted.
\end{abstract}

Keywords: Fruit processing; Food hygiene; Food safety; Legislation. 


\begin{abstract}
Resumen
Esta revisión ofrece un panorama de la calidad microbiológica de las pulpas de frutas comercializadas en Brasil, por medio de una revisión integradora de trabajos publicados entre los años 2010 y 2020 . Se consultaron tres bases de datos (Académico de Google, Scientific Electronic Library Online y Biblioteca Virtual Health), utilizando los descriptores: pulpa de fruta, calidad, calidad microbiológica y calidad higiénico-sanitaria. Los resultados de la búsqueda fueron evaluados y seleccionados, considerando el objetivo del estudio, así como los factores de inclusión y exclusión. Se seleccionaron 56 estudios para la evaluación, descripción, discusión y síntesis del conocimiento producido por meio de ellos. Traz la evaluación, se encontró un 94,6\% de los trabajos se publicaron en portugués y 44,6\% se realizaron en el noreste de Brasil. Lo general, los análisis microbiológicos se realizaron por métodos convencionales $(87,5 \%)$ y los parámetros más evaluados fueron el recuento de coliformes termotolerantes $(71,4 \%)$, investigación de Salmonella sp. $(64,3 \%)$, recuento de mohos y levaduras $(60,7 \%)$ y recuento de coliformes totales $(58,9 \%)$. Los trabajos que realizaron el recuento de coliformes termotolerantes, recuento de mohos y levaduras e evaluación de Salmonella sp., 31,7\%, 67,7\% y 16,7\%, respectivamente, presentaron al menos una muestra en desacuerdo con los límites permitidos por la legislación brasileña. Los resultados de los estudios evaluados demostraron que el procesamiento de pulpas de frutas en Brasil todavía enfrenta problemas de parámetros con respecto a los estándares microbiológicos requeridos y límites considerados seguros para la comercialización de este producto. En este contexto, se destaca la necesidad de una mayor vigilancia e inspección del procesamiento de pulpas de frutas comercializadas en el territorio brasileño.
\end{abstract}

Palabras clave: Frutas procesadas; Legislación; Microbiología.

\title{
1. Introdução
}

O Brasil destaca-se na produção de frutas, sendo um dos maiores produtores mundiais e detentor de uma flora diversificada devido às suas dimensões continentais e variedades climáticas (Costa et al., 2020). Assim, o setor da agroindústria brasileira tem o desafio de garantir, através de operações unitárias e métodos de conservação, a máxima preservação das características físico-químicas, nutricionais e sensoriais dos produtos à base de frutas produzidas no território nacional (Silva et al., 2015). Nesse cenário, o processamento de polpa de frutas é uma alternativa que minimiza os desperdícios e permite que as frutas sazonais sejam usadas em qualquer época do ano, seja pelo consumidor para uso doméstico, ou mesmo para fins industriais, como matéria-prima para outros produtos alimentícios (sucos, sorvetes, doces e laticínios) (Silva \& Abud, 2017).

O consumo de frutas e polpa de frutas entre a população tem aumentado concomitantemente com o crescimento da busca por estilo de vida saudável e redução de consumo de bebidas açucaradas (Silva et al., 2014). A polpa de fruta torna-se uma alternativa prática para uma população cada vez mais dinâmica, em especial pela facilidade de estocagem e de preparo para o consumo doméstico e institucional. Nesse sentido, a produção de polpa de fruta no Brasil tem aumentado pela alta demanda do mercado e, adicionalmente, por apresentar um fluxograma de processamento simples e de baixo custo (Machado et al., 2007). Todavia, a expansão de consumo de polpa de fruta no Brasil tem promovido um aumento da abertura de empresas de pequeno porte e estimulado o mercado informal (Santos et al., 2016b). Consequentemente, esse cenário gera uma alta na incidência de produção e comercialização de polpa de frutas em desacordo com padrões de identidade e qualidade estabelecidos pela legislação, gerando produtos sem uniformidade e com inocuidade duvidosa.

Em geral, os problemas de qualidade e segurança de polpa de frutas estão relacionados com irregularidades nas etapas de higienização (limpeza e sanitização) e cadeia do frio (congelamento) (Silva et al., 2016a). Desse modo, a qualidade e a segurança de polpas de frutas podem ser monitoradas através de parâmetros físico-químicos e microbiológicos. Os parâmetros físico-químicos estão intrinsecamente relacionados com a uniformidade e aceitação sensorial do produto final. Enquanto os parâmetros microbiológicos permitem o monitoramento das condições de processamento, armazenamento, distribuição, prazo de validade e risco para a saúde pública (Silva \& Abud, 2017).

O risco para saúde do consumidor decorre da presença de micro-organismos patogênicos ou de condições de processamento que possam permitir a proliferação destes. A contaminação de produtos processados de frutas pode ocorrer nas etapas de pré e pós-colheita (Alegbeleye et al., 2018). Entre os fatores que podem favorecer a contaminação das frutas frescas, 
antes da colheita, destacam-se a contaminação do solo e da água de irrigação e o uso de excrementos de animais como fertilizante. Enquanto isso, os fatores que estão relacionados com a contaminação nas etapas que ocorrem após a colheita estão geralmente relacionados as falhas de higiene por parte do manipulador, ou mesmo, contaminação de equipamentos, utensílios e veículos de transporte. Além disso, o uso de água de lavagem contaminada, irregularidades no armazenamento e embalagens impróprias também são aspectos importantes na contaminação de polpa de frutas (Sant'anna et al., 2020).

Durante quase duas décadas os padrões microbiológicos para polpa de frutas produzidas no Brasil eram estabelecidos através da Instrução Normativa $n^{\circ} 01$ de 07 de janeiro de 2000 do Ministério da Agricultura, Pecuária e Abastecimento (MAPA) (Brasil, 2000) e da Resolução RDC n 12, de 02 de janeiro de 2001 da Agência Nacional de Vigilância Sanitária (ANVISA) (Brasil, 2001). Todavia, em 2018 o MAPA publicou uma nova Instrução Normativa, $\mathrm{n}^{\circ}$ 49, de 26 de setembro de 2018 (Brasil, 2018). Outrossim, no ano seguinte a ANVISA publicou a instrução normativa nº 60, de 23 de dezembro de 2019 (Brasil, 2019). Com essa publicação, a ANVISA unificou os padrões microbiológicos que eram discrepantes entre os dois órgãos vigentes no país (Brasil, 2000; Brasil, 2001). No lugar da enumeração de coliformes termotolerantes, que aparecia em ambas as legislações anteriores, estabeleceu-se a enumeração de Escherichia coli. A ausência de Salmonella, que já constava nas duas legislações antigas, continuou presente na nova legislação. Enquanto, a enumeração de bolores e leveduras, que somente era contemplada como parâmetro na Instrução Normativa do MAPA, foi então adicionada a Instrução Normativa ${ }^{\circ}$ 60/2019, atualmente vigente.

A segurança de alimentos é um importante pilar no campo da saúde pública, devido ao grande número de enfermidades que podem ser transmitidas através da ingestão de alimentos (Truchado \& Allende, 2020). Mundialmente, estima-se que cerca de 9 milhões de pessoas por ano, sejam acometidas por doenças transmitidas por alimentos e muitos casos resultam em hospitalizações e óbitos (Ding et al., 2017). No Brasil, o Ministério da Saúde, através da Agência Nacional de Vigilância Sanitária (ANVISA), e o Ministério da Agricultura, Pecuária e Abastecimento (MAPA) são responsáveis por monitorar e fiscalizar a padronização e inocuidade dos alimentos (Elias et al., 2018).

Em adição, as publicações acadêmicas que investigam a qualidade microbiológica de alimentos produzidos e comercializados no país, possuem um importante papel para a saúde pública. Os resultados de pesquisas científicas são importantes fontes de informações para autoridades da área de saúde e profissionais da indústria de alimentos. Nessa perspectiva, as revisões integrativas surgem como uma alternativa promissora de estudos que objetivam sintetizar resultados obtidos em pesquisas sobre um tema ou questão, de maneira sistemática, ordenada e abrangente (Souza et al., 2010). Esse tipo de estudo é bastante utilizado na área da saúde, em especial na área de enfermagem e medicina, como fundamentação para prática baseada em evidências (Ercole et al., 2014), porém várias áreas de conhecimento têm feito uso dessa metodologia com objetivo de sintetizar conhecimento (Paiva et al., 2016; Esper \& Cunha, 2015; Silva et al., 2015; Botelho et. al., 2011).

Assim, revisões integrativas acerca da qualidade microbiológica de produtos alimentícios produzidos no território nacional, fornecem informações que podem auxiliar na tomada de decisão e criação de estratégias utilizadas na prevenção e controle de patógenos em linhas de produção. Além disso, a divulgação de um compilado de resultados oriundos de vários estudos é importante para a sensibilização do setor da agroindústria sobre a importância das boas práticas de fabricação e controle de qualidade em toda cadeia produtiva de alimentos. Nesse contexto, esta revisão integrativa tem como objetivo trazer uma visão geral acerca da qualidade microbiológica de polpas de frutas comercializadas no Brasil entre os anos de 2010 e 2020.

\section{Metodologia}

O presente estudo trata-se de uma revisão integrativa, método que sintetiza sistematicamente o conhecimento científico produzido em um dado período de tempo. A questão de pesquisa norteadora da revisão integrativa foi: "Quais as 
condições higiênico-sanitárias das polpas de frutas produzidas e comercializadas no Brasil no período de 2010 a 2020 ? ".

A pesquisa bibliográfica foi realizada de dezembro de 2020 a janeiro de 2021, por meio de busca eletrônica nas seguintes bases de dados: Google acadêmico, Scientific Electronic Library Online (SCIELO) e Biblioteca Virtual da Saúde (BVS). A busca on-line nas bases de dados ocorreu mediante consulta dos termos/descritores nos idiomas português e inglês: polpa de frutas (fruit pulp), qualidade (quality), qualidade microbiológica (microbiology quality), qualidade higiênico-sanitária (hygienic-sanitary quality). Com o intuito de garantir uma busca eficiente fez-se uso do operador booleano "and" para cruzar os descritores da seguinte forma: "polpas de frutas and qualidade microbiológica", "fruit pulp and microbiology quality", "polpas de frutas and qualidade", "fruit pulp and quality", "polpas de frutas and qualidade higiênico-sanitária" e "fruit pulp and hygienic-sanitary quality".

Foram incluídos nesse estudo artigos originais, que respondiam à questão norteadora, nos idiomas português ou inglês, publicados em periódicos científicos e disponíveis na íntegra no período de 2010 a 2020. A delimitação desse período é justificada pela avaliação das condições higiênico-sanitárias de polpa de frutas produzidas e comercializadas na última década no Brasil. Foram excluídos os editoriais (cartas, comentários, notas breves), cartas ao editor, estudos de revisão, resenhas, trabalhos de conclusão de curso, teses, dissertações, monografias e resumos publicados em anais de eventos. Os artigos em duplicidade foram considerados uma única vez, respeitando a ordem pesquisada das bases de dados. O processo de busca e seleção dos estudos seguiu as recomendações Statement for Reporting Systematic Reviews and Meta-Analyses of Studie (PRISMA) (Moher et al., 2009), conforme apresentado na Figura 1.

Figura 1. Fluxograma PRISMA, de seleção dos estudos que compuseram a amostra.

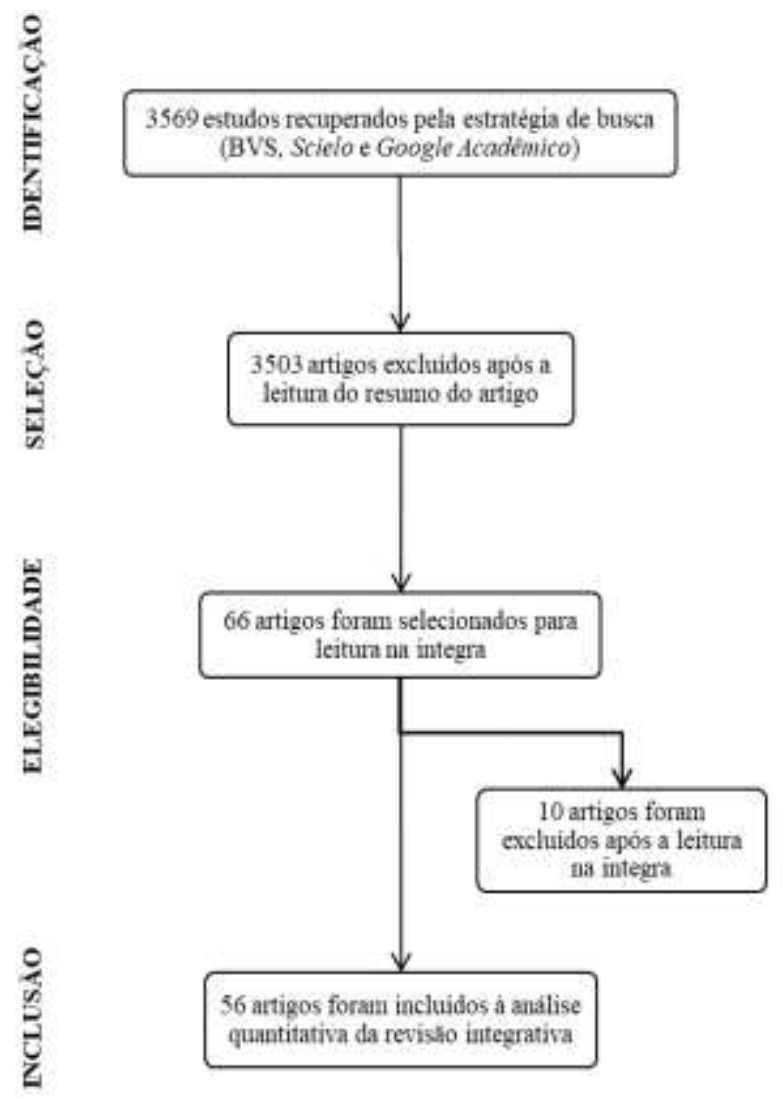

Fonte: Autores. 
As publicações foram analisadas, interpretadas e apresentadas em um quadro sinóptico contendo as principais informações acerca dos estudos, a citar: apresentação de autores, ano de publicação, estado de realização da pesquisa, número de amostras avaliadas, descrição da amostra, parâmetros microbiológicos avaliados e principais resultados. Ao fim da análise e descrição dos estudos realizou-se a discussão dos resultados encontrados e a síntese do conhecimento produzido através desse estudo.

\section{Resultados e Discussão}

O total de 56 artigos foram selecionados para análise neste estudo e foram apresentados e descritos no Quadro 1, destes 94,6\% (53) foram publicados na língua portuguesa e 5,4\% (3) na língua inglesa. Quanto a região do país de realização dos estudos, 46,4\% (26) estudos foram realizados no Nordeste, 23,2\% (13) no Norte, 23,2\% (13) no Sudeste, 3,6\% (2) no Sul e $3,6 \%$ (2) no Centro-oeste.

O banco de dados Google acadêmico apresentou 100\% dos artigos discutidos neste estudo. Enquanto isso, 14,3\% dos artigos (8/56) foram também encontrados no banco Biblioteca Virtual da Saúde (BVS). Todavia, no banco de dados Scientific Electronic Library Online (SCIELO) somente foram encontrados 3,6\% dos artigos (2/56), sendo um igualmente encontrado no banco Google acadêmico (Santos et al., 2016b) e outro encontrado em todos os bancos de dados usados para busca (Coutinho et al., 2017).

Quanto aos parâmetros microbiológicos avaliados nos estudos selecionados, verificou-se que os parâmetros mais utilizados foram a enumeração de coliformes termotolerantes (41 estudos), pesquisa de Salmonella sp. (36 estudos), enumeração de bolores e leveduras (34 estudos) e enumeração de coliformes totais (33 estudos). Além desses, outros parâmetros foram investigados por uma menor parcela de estudos, a citar: detecção de Escherichia coli (16 estudos), enumeração de bactérias aeróbias mesófilas (10 estudos) e enumeração de Staphylococcus aureus (4 estudos). Adicionalmente, um estudo em particular realizou a pesquisa de enterobactérias (Nascimento et al., 2013) e outro estudo realizou pesquisa de Listeria monocytogenes (Barcelos et al., 2017).

A maioria dos estudos avaliados fez uso de métodos convencionais de análise microbiológica, sendo que 87,5\% (49) dos estudos fizeram uso exclusivo deste método. Quanto ao uso de métodos rápidos de análise microbiológica, 12,5\% dos estudos (7) fizeram uso de testes rápidos.

Do total de estudos que realizaram a análise para enumeração de coliformes termotolerantes, enumeração de bolores e leveduras e pesquisa de Salmonella sp., 68,3\% (28/41), 30,3\% (10/33) e 83,3\% (30/36) das amostras, respectivamente, apresentaram-se em conformidade com os limites permitidos pela legislação brasileira (Brasil, 2000; Brasil, 2001). 
Quadro 1. Síntese dos estudos (n=56) incluídos nesta revisão integrativa.

\begin{tabular}{|c|c|c|c|c|}
\hline Referências & Cidade - Estado & $\begin{array}{l}\text { Número e amostras } \\
\text { avaliadas }\end{array}$ & $\begin{array}{l}\text { Parâmetros microbiológicos } \\
\text { estudados }\end{array}$ & Principais resultados \\
\hline Eto et al. (2010) & São Carlos - SP & $\begin{array}{l}\text { n.: } 6 \\
\text { Polpas de fruta (açaí) }\end{array}$ & $\begin{array}{l}\text { - Coliformes totais e } \\
\text { termotolerantes* } \\
\text { - Salmonella } \text { sp. }^{*} \\
\end{array}$ & Ausência de Salmonella sp., coliformes totais e termotolerantes. \\
\hline Amorim et al. (2010) & Itapetinga - BA & $\begin{array}{l}\text { n.: } 8 \\
\text { Polpas de frutas } \\
\text { (goiaba, acerola, cacau } \\
\text { e abacaxi) }\end{array}$ & - Coliformes totais & $\begin{array}{l}\text { A enumeração de coliformes totais apresentaram valores menores que } 0,3 \\
\text { NMP. } \mathrm{g}^{-1} \text {. }\end{array}$ \\
\hline Macena et al. (2010) & Teixeira de Freitas - BA & $\begin{array}{l}\text { n.: } 72 \\
\text { Polpas de frutas } \\
\text { (acerola, cacau e cajá) }\end{array}$ & $\begin{array}{l}\text { - Coliformes totais e } \\
\text { termotolerantes } \\
\text { - Bolores e leveduras }\end{array}$ & $\begin{array}{l}\text { Apenas uma amostra }(1,4 \%) \text { estava fora para os padrões de coliformes } \\
\text { termotolerantes e todas as amostras estavam em conformidade com } \\
\text { legislação }{ }^{1} \text { quanto as contagens de bolores e leveduras. }\end{array}$ \\
\hline Cohen et al. (2011) & Belém - PA & $\begin{array}{l}\mathrm{n} .: 10 \\
\text { Polpas de fruta (açaí) }\end{array}$ & $\begin{array}{l}\text { - Coliformes termotolerantes } \\
\text { - Escherichia coli } \\
\text { - Salmonella sp. } \\
\text { - Bolores e leveduras }\end{array}$ & $\begin{array}{l}\text { Todas as amostras apresentaram valores } \geq 1,1 \times 10^{2} \mathrm{NMP}^{-1} \text { de coliformes } \\
\text { termotolerantes. Além disso, em nove amostras foram detectadas a } \\
\text { presença de E. coli e em duas destas, foi detectada a presença de } \\
\text { Salmonella sp.. Em todas as amostras foram observadas contagens de } \\
\text { bolores e leveduras acima do permitido pela legislação }{ }^{1} \text {, variando de } 9,0 \mathrm{x} \\
10^{2} \mathrm{NMP} \cdot \mathrm{g}^{-1} \text { a } 5,5 \times 10^{5} \text { UFC. } \mathrm{g}^{-1} \text {. }\end{array}$ \\
\hline Souza et al. (2011) & Russas - CE & $\begin{array}{l}\text { n.: } 12 \\
\text { Polpas de frutas } \\
\text { (acerola, goiaba, manga, } \\
\text { cajá, caju, } \\
\text { mamão, melão, abacaxi, } \\
\text { siriguela, umbu, } \\
\text { maracujá e } \\
\text { graviola) }\end{array}$ & $\begin{array}{l}\text { - Coliformes termotolerantes } \\
\text { - Escherichia coli } \\
\text { - Salmonella sp. } \\
\text { - Bolores e leveduras }\end{array}$ & $\begin{array}{l}\text { As contagens de coliformes totais variaram entre }<3,0 \text { a } 75 \mathrm{NMP}^{-1}{ }^{-1} \text {. As } \\
\text { polpas analisadas encontravam-se dentro dos padrões estabelecidos pela } \\
\text { legislação }{ }^{1} \text { vigente com relação a coliformes termotolerantes. Observou-se } \\
\text { ausência de E. coli e Salmonella sp. nas amostras, porém } 50 \% \text { das } \\
\text { amostras apresentaram valores acima do permitido pela legislação }{ }^{2} \text { para } \\
\text { bolores e leveduras. }\end{array}$ \\
\hline Dantas et al. (2012) & Campina Grande - PB & $\begin{array}{l}\text { n.: } 19 \\
\text { Polpas de frutas (cajá, } \\
\text { caju, acerola, goiaba, } \\
\text { abacaxi e uva) }\end{array}$ & $\begin{array}{l}\text { - Coliformes totais e } \\
\text { termotolerantes } \\
\text { - Salmonella sp. } \\
\text { - Bolores e leveduras } \\
\text { - Staphylococcus aureus }\end{array}$ & $\begin{array}{l}\text { Para coliformes totais foram encontrados valores que variaram de } 3,0 \text { a } 3,6 \\
\text { NMP.g } \mathrm{g}^{-1} \text {. Apenas uma amostra estava acima do valor permitido pela } \\
\text { legislação para coliformes termotolerantes. Salmonella sp. estava presente } \\
\text { em quatro amostras. Para bolores e leveduras duas amostras estavam acima } \\
\text { do valor permitido pela legislação } 0^{2} \text {. A enumeração de } S \text {. aureus variou de } \\
10 \text { a } 4,6 \times 10^{3} \text { UFC. }^{-1} \text {. }\end{array}$ \\
\hline Farias et al. (2012) & Pouso Alegre - MG & $\begin{array}{l}\text { n.: } 36 \\
\text { Polpas de fruta (açaí) }\end{array}$ & $\begin{array}{l}\text { - Coliformes totais e } \\
\text { termotolerantes } \\
\text { - Escherichia coli } \\
\text { - Bolores e leveduras } \\
\text { - Bactérias aeróbias mesófilas }\end{array}$ & $\begin{array}{l}\text { A enumeração de coliformes totais variou entre }<3,0 \text { e } 2,3 \times 10^{1} \mathrm{NMP}^{-1} \mathrm{~g}^{-1} \text {. } \\
\text { Cinco amostras }(16,7 \%) \text { apresentaram coliformes termotolerantes acima } \\
\text { do valor permitido pela legislação }{ }^{1} \text { e } 13,8 \% \text { confirmaram presença para } E \text {. } \\
\text { coli. Além disso, foram observadas contagens de bolores e leveduras } \\
\text { acima do valor permitido pela legislação }{ }^{2} \text { em } 8,3 \% \text { das amostras. Com } \\
\text { relação à contagem de bactérias mesófilas, os valores oscilaram entre } 3 \times \\
10^{1} \text { a } 3,3 \times 10^{4} \text { UFC. } \mathrm{g}^{-1} \text {. }\end{array}$ \\
\hline
\end{tabular}




\begin{tabular}{|c|c|c|c|c|}
\hline Santos \& Barros (2012) & Paragominas - PA & $\begin{array}{l}\text { n.: } 6 \\
\text { Polpas de frutas } \\
\text { (goiaba, acerola e } \\
\text { maracujá) }\end{array}$ & $\begin{array}{l}\text { - Coliformes termotolerantes } \\
\text { - Salmonella } \mathrm{sp.}\end{array}$ & $\begin{array}{l}\text { As análises para coliformes termotolerantes em conformidade com } \\
\text { legislação }{ }^{1} \text { e ausência de Salmonella sp.. }\end{array}$ \\
\hline Urbano et al. (2012) & Londrina - PR & $\begin{array}{l}\mathrm{n} .: 10 \\
\text { Polpas de fruta (acerola) }\end{array}$ & $\begin{array}{l}\text { - Coliformes totais e } \\
\text { termotolerantes } \\
\text { - Bolores e leveduras }\end{array}$ & $\begin{array}{l}\text { Ausência de coliformes totais e termotolerantes. Igualmente, não houve } \\
\text { enumeração de bolores e leveduras. }\end{array}$ \\
\hline Batista et al. (2013) & Datas - MG & $\begin{array}{l}\text { n.: } 20 \\
\text { Polpas de frutas } \\
\text { (acerola, caju, goiaba, } \\
\text { manga, maracujá, } \\
\text { morango, abacaxi, } \\
\text { mamão e tamarindo) }\end{array}$ & $\begin{array}{l}\text { - Coliformes totais } \\
\text { - Bolores e leveduras } \\
\text { - Salmonella sp. }\end{array}$ & $\begin{array}{l}\text { Os resultados das análises microbiológicas para detecção de Salmonella } \\
\text { sp. e coliformes totais nas polpas congeladas mostraram que estas se } \\
\text { encontravam de acordo com a legislaçãa }{ }^{2} \text { vigente. Em relação a bolores e } \\
\text { leveduras, } 60 \% \text { das polpas analisadas mostraram-se em desacordo com a } \\
\text { legislação }{ }^{2} \text {. }\end{array}$ \\
\hline $\begin{array}{l}\text { Ferreira-Marçal et al. } \\
\text { (2013) }\end{array}$ & Governador Valadares -MG & $\begin{array}{l}\text { n.: } 9 \\
\text { Polpas de frutas } \\
\text { (acerola, cacau, caju, } \\
\text { cupuaçu, goiaba, } \\
\text { graviola, mamão, } \\
\text { manga e uva) }\end{array}$ & $\begin{array}{l}\text { - Coliformes totais e } \\
\text { termotolerantes } \\
\text { - Salmonella sp. } \\
\text { - Bolores e leveduras }\end{array}$ & $\begin{array}{l}\text { Não foi detectado presença de Salmonella sp., coliformes totais e } \\
\text { termotolerantes nas amostras. Apenas uma amostra apresentou contagem } \\
\text { acima do permitido pela legislação }{ }^{2} \text { para bolores e leveduras }\left(2,1 \times 10^{3}\right. \\
\left.\text { UFC. } \mathrm{g}^{-1}\right) \text {. }\end{array}$ \\
\hline Nascimento et al. (2013) & São Luís - MA & $\begin{array}{l}\text { n.: } 50 \\
\text { Polpas de frutas (bacuri, } \\
\text { caju, cajá, cupuaçu, } \\
\text { goiaba, acerola, } \\
\text { cupuaçu, graviola, } \\
\text { maracujá) }\end{array}$ & - Contagem de enterobactérias & $\begin{array}{l}\text { A contaminação por enterobactérias foi observada em } 32 \% \text { das polpas } \\
\text { analisadas com valores variando entre } 1,6 \times 10^{5} \mathrm{e} 5,8 \times 10^{6} \mathrm{UFC}^{-1} \text {. }\end{array}$ \\
\hline Silva et al. (2013) & São Luís - MA & $\begin{array}{l}\text { n.: } 21 \\
\text { Polpas de fruta } \\
\text { (cupuaçu) }\end{array}$ & $\begin{array}{l}\text { - Coliformes termotolerantes } \\
\text { - Salmonella } \mathrm{sp.}\end{array}$ & Ausência de coliformes termotolerantes e Salmonella sp.. \\
\hline Arcanjo et al. (2014) & Imperatriz - MA & $\begin{array}{l}\text { n.: } 8 \\
\text { Polpas de fruta (açaí) }\end{array}$ & $\begin{array}{l}\text { - Coliformes totais* } \\
\text { - Escherichia coli* }\end{array}$ & $\begin{array}{l}\text { As enumerações de coliformes totais variaram de } 2,0 \times 10^{2} \text { a } 2,4 \times 10^{3} \\
\text { NMP.g }{ }^{-1} \text {. E. coli não foi detectada em nenhuma amostra. }\end{array}$ \\
\hline Jones \& Lemes (2014) & Itajubá - MG & $\begin{array}{l}\text { n.: } 10 \\
\text { Polpas de fruta (açaí) }\end{array}$ & $\begin{array}{l}\text { - Coliformes termotolerantes } \\
\text { - Escherichia coli } \\
\text { - Salmonella sp. } \\
\text { - Bactérias aeróbias mesófilas }\end{array}$ & $\begin{array}{l}\text { Cinco amostras apresentaram valores acima do valor permitido pela } \\
\text { legislação }{ }^{1} \text { para coliformes termotolerantes com confirmação da presença } \\
\text { de } E \text {. coli. Todas amostras apresentaram ausência de Salmonella sp.. Para a } \\
\text { contagem de bactérias aeróbias mesófilas observou-se duas amostras com } \\
\text { contagens acima de } 10^{6} \mathrm{UFC}^{-1} \mathrm{~g}^{-1} \text {. }\end{array}$ \\
\hline $\begin{array}{l}\text { Santos \& Nascimento } \\
\text { (2014) }\end{array}$ & São Luís - MA & $\begin{array}{l}\text { n.: } 53 \\
\text { Polpas de frutas } \\
\text { (acerola, bacuri, } \\
\text { cupuaçu e goiaba) }\end{array}$ & $\begin{array}{l}\text { - Coliformes termotolerantes } \\
\text { - Salmonella sp. } \\
\text { - Bolores e leveduras }\end{array}$ & $\begin{array}{l}\text { Do total de amostras avaliadas, } 18,9 \% \text { (10) apresentaram contagens de } \\
\text { coliformes termotolerantes acima do valor permitido pela legislação }{ }^{1} \text {. } \\
\text { Todas as amostras apresentaram ausência de Salmonella sp. e } \\
\text { apresentaram enumeração de bolores e leveduras acima do valor permitido } \\
\text { pela legislação }{ }^{2} \text {. }\end{array}$ \\
\hline Castro et al. (2015) & Cuiabá - MT & $\begin{array}{l}\mathrm{n} .: 54 \\
\text { Polpas de frutas }\end{array}$ & $\begin{array}{l}\text { - Coliformes totais e } \\
\text { termotolerantes }\end{array}$ & $\begin{array}{l}\text { Todas as amostras apresentaram ausência de contagens de coliformes } \\
\text { totais, coliformes termotolerantes e Salmonella sp.. Toda as amostras }\end{array}$ \\
\hline
\end{tabular}




\begin{tabular}{|c|c|c|c|c|}
\hline & & $\begin{array}{l}\text { (acerola, goiaba e } \\
\text { maracujá) }\end{array}$ & $\begin{array}{l}\text { - Salmonella sp. } \\
\text { - Bolores e leveduras }\end{array}$ & $\begin{array}{l}\text { apresentaram valores dentro dos limites permitidos pela legislação }{ }^{2} \text { para } \\
\text { bolores e leveduras. }\end{array}$ \\
\hline Chesca et al. (2015) & Uberaba - MG & $\begin{array}{l}\text { n.: } 30 \\
\text { Polpas de fruta (acerola) }\end{array}$ & $\begin{array}{l}\text { - Coliformes termotolerantes } \\
\text { - Salmonella sp. }\end{array}$ & $\begin{array}{l}\text { Todas as amostras apresentaram ausência de coliformes termotolerantes e } \\
\text { Salmonella sp.. }\end{array}$ \\
\hline Freitas et al. (2015) & $\begin{array}{l}\text { Governador Valadares - } \\
\text { MG }\end{array}$ & $\begin{array}{l}\text { n.: } 3 \\
\text { Polpas de fruta (açaí) }\end{array}$ & $\begin{array}{l}\text { - Coliformes totais } \\
\text { - Salmonella sp. } \\
\text { - Bolores e leveduras }\end{array}$ & $\begin{array}{l}\text { Todas as amostras não apresentaram crescimento de coliformes totais. } \\
\text { Observou-se ausência de Salmonella sp. nas amostras. Duas das amostras } \\
\text { apresentaram enumeração acima do permitido pela legislação }{ }^{2} \text { para bolores } \\
\text { e leveduras. }\end{array}$ \\
\hline Santos et al. (2015) & Campinas - SP & $\begin{array}{l}\text { n.: } 5 \\
\text { Polpas de frutas } \\
\text { (laranja, framboesa, } \\
\text { maracujá, morango e } \\
\text { açaí) }\end{array}$ & $\begin{array}{l}\text { - Coliformes totais e } \\
\text { termotolerantes } \\
\text { - Salmonella } \mathrm{sp.} \\
\text { - Bolores e leveduras } \\
\text { - Bactérias aeróbias mesófilas }\end{array}$ & $\begin{array}{l}\text { As enumerações de coliformes totais e termotolerantes foi }<3,0 \mathrm{NMP} \cdot \mathrm{g}^{-1} \\
\text { para todas as amostras. Observou-se ausência de Salmonella sp. em todas } \\
\text { as amostras. As enumerações de bolores e leveduras apresentaram valores } \\
\text { abaixo do limite permitido pela legislação }{ }^{2} \text {. As contagens de bactérias } \\
\text { aeróbias mesófilas apresentaram-se abaixo de } 10^{4} \mathrm{UFC}^{-1} \mathrm{~g}^{-1} \text { com intervalo } \\
\text { de }<10 \text { a } 8,8 \times 10^{2} \text { UFC. } \mathrm{g}^{-1} \text {. }\end{array}$ \\
\hline Faria et al. (2016) & Cuiabá - MT & $\begin{array}{l}\text { n.: } 25 \\
\text { Polpas de frutas } \\
\text { (abacaxi, acerola, caju, } \\
\text { goiaba, maracujá) }\end{array}$ & $\begin{array}{l}\text { - Coliformes termotolerantes } \\
\text { - Salmonella } \text { sp. } \\
\text { - Bolores e leveduras }\end{array}$ & $\begin{array}{l}\text { Nenhuma das amostras excedeu o valor máximo permitido pela legislação }{ }^{1} \\
\text { para coliformes termotolerantes. Todavia, } 12 \% \text { do total das amostras } \\
\text { analisadas apresentaram-se com valores acima dos limites permitidos pela } \\
\text { legislação }{ }^{2} \text { para bolores e leveduras. Todas as amostras apresentaram } \\
\text { ausência de Salmonella sp.. }\end{array}$ \\
\hline Fechine Neto et al. (2016) & Missão Velha - CE & $\begin{array}{l}\text { n.: } 20 \\
\text { Polpas de frutas } \\
\text { (maracujá, tamarindo, } \\
\text { morango e caju) }\end{array}$ & $\begin{array}{l}\text { - Coliformes totais e } \\
\text { termotolerantes } \\
\text { - Escherichia coli } \\
\text { - Bolores e leveduras }\end{array}$ & $\begin{array}{l}\text { Todas as amostras apresentaram-se em conformidade para os limites } \\
\text { permitidos pela legislação para enumeração de coliformes } \\
\text { termotolerantes. Nenhuma das amostras apresentou coliformes totais e } E \text {. } \\
\text { coli. Todavia, três amostras mostraram-se com valores acima do limite } \\
\text { permitido pela legislação }{ }^{2} \text { para enumeração de bolores e leveduras }\left(>10^{5}\right. \\
\left.\text { UFC. } \mathrm{g}^{-1}\right) \text {. }\end{array}$ \\
\hline Santos et al. (2016)a & São Paulo - SP & $\begin{array}{l}\text { n.: } 20 \\
\text { Polpas de fruta (açaí) }\end{array}$ & $\begin{array}{l}\text { - Identificação de micro- } \\
\text { organismos patogênicos }\end{array}$ & $\begin{array}{l}\text { Foram detectadas bactérias do gênero Staphylococcus sp. (50\%), } \\
\text { Enterobacter sp. }(25 \%) \text {, Serratia sp. }(15 \%) \text { e E. coli }(10 \%) \text {, sendo que em } \\
\text { algumas das amostras teve o crescimento de mais de uma espécie } \\
\text { bacteriana. }\end{array}$ \\
\hline Santos et al. (2016)b & $\begin{array}{l}\text { Petrolina -PE e Juazeiro - } \\
\text { BA }\end{array}$ & $\begin{array}{l}\text { n.: } 28 \\
\text { Polpas de frutas (uva, } \\
\text { manga, cajá, caju, } \\
\text { abacaxi, tamarindo e } \\
\text { maracujá) }\end{array}$ & $\begin{array}{l}\text { - Coliformes totais e } \\
\text { termotolerantes } \\
\text { - Bolores e leveduras }\end{array}$ & $\begin{array}{l}\text { As contagens de coliformes totais variaram entre } 0 \text { e } 300 \mathrm{NMP}^{-1}{ }^{-1} \text { Todas } \\
\text { as amostras apresentaram-se em conformidade para os limites permitidos } \\
\text { pela legislaçã̃o para enumeração de coliformes termotolerantes. Todavia, } \\
\text { seis amostras estavam acima do limite estabelecido pela legislação }{ }^{2} \text { para } \\
\text { bolores e leveduras. }\end{array}$ \\
\hline Silva et al. (2016)a & Alagoas & $\begin{array}{l}\text { n.:17 } \\
\text { Polpas de frutas } \\
\text { (abacaxi, açaí, acerola, } \\
\text { ameixa, cajá, caju, } \\
\text { cupuaçu, goiaba, }\end{array}$ & $\begin{array}{l}\text { - Coliformes totais e } \\
\text { termotolerantes } \\
\text { - Bolores e leveduras }\end{array}$ & $\begin{array}{l}\text { Todas as amostras apresentaram contagens de coliformes totais }<3,0 \\
\text { NMP.g }{ }^{-1} \text {. As contagens de coliformes termotolerantes apresentaram } \\
\text { valores abaixo do limite estabelecido pela legislação }{ }^{1} \text {. Quanto a } \\
\text { enumeração de bolores e leveduras, } 30 \% \text { das amostras apresentaram } \\
\text { valores acima do limite estabelecido pela legislação }{ }^{2} \text {. }\end{array}$ \\
\hline
\end{tabular}




\begin{tabular}{|c|c|c|c|c|}
\hline & & $\begin{array}{l}\text { graviola, manga, } \\
\text { mangaba, maracujá, } \\
\text { morango, pitanga, } \\
\text { tamarindo, tangerina e } \\
\text { uva) }\end{array}$ & & \\
\hline Silva et al. (2016)b & Salvador - BA & $\begin{array}{l}\text { n.: } 9 \\
\text { Polpas de fruta (manga) }\end{array}$ & $\begin{array}{l}\text { - Coliformes totais e } \\
\text { termotolerantes } \\
\text { - Bolores e leveduras }\end{array}$ & $\begin{array}{l}\text { As contagens de coliformes totais variaram entre } 1,4 \text { a } 1.100 \mathrm{NMP}^{-1} \mathrm{~g}^{-1} \text {. As } \\
\text { enumerações de coliformes termotolerantes mostraram que } 11,1 \% \text { das } \\
\text { amostras estavam em desacordo com a legislação }{ }^{1} \text {. Em contraste, } 100 \% \\
\text { das amostras estavam em desacordo com os padrões microbiológicos } \\
\text { estabelecidos pela legislação }{ }^{2} \text { para o limite de bolores e leveduras. }\end{array}$ \\
\hline Souza et al. (2016) & Juazeiro do Norte - CE & $\begin{array}{l}\text { n.: } 40 \\
\text { Polpas de frutas } \\
\text { (acerola, abacaxi, cajá, } \\
\text { goiaba, graviola, } \\
\text { mamão, manga e } \\
\text { maracujá) }\end{array}$ & $\begin{array}{l}\text { - Salmonella } \mathrm{sp.} \\
\text { - Escherichia coli } \\
\text { - Staphylococcus aureus }\end{array}$ & $\begin{array}{l}\text { Foi identificada Salmonella sp. em duas amostras. Entretanto, E. coli não } \\
\text { foi detectado em nenhuma das amostras. S. aureus estava presente em } 31 \\
\text { amostras. }\end{array}$ \\
\hline Teixeira et al. (2016) & Vitória da Conquista - BA & $\begin{array}{l}\text { n.: } 3 \\
\text { Polpas de fruta (manga) }\end{array}$ & $\begin{array}{l}\text { - Coliformes totais e } \\
\text { termotolerantes** } \\
\text { - Escherichia coli* } \\
\text { - Salmonella } \text { sp. } \\
\text { - Bolores e leveduras* } \\
\text { - Bactérias aeróbias mesófilas* }\end{array}$ & $\begin{array}{l}\text { As amostras não apresentaram crescimento para coliformes totais e } \\
\text { termotolerantes. Verificou-se ausência de } E \text {. coli e Salmonella sp. Todavia, } \\
\text { para bolores e leveduras, uma das amostras apresentou valor acima dos } \\
\text { permitidos pela legislação }{ }^{2} \text {. As contagens de bactérias aeróbias mesófilas } \\
\text { apresentaram uma variação entre } 4,0 \times 10^{1} \text { e } 1,0 \times 10^{2} \text { UFC. } \mathrm{g}^{-1} \text {. }\end{array}$ \\
\hline Alvarenga et al. (2017) & Muriaé - MG & $\begin{array}{l}\text { n.: } 40 \\
\text { Polpas de frutas } \\
\text { (abacaxi, acerola, caju, } \\
\text { laranja, maracujá e } \\
\text { morango) }\end{array}$ & $\begin{array}{l}\text { - Coliformes totais e } \\
\text { termotolerantes } \\
\text { - Bolores e leveduras }\end{array}$ & $\begin{array}{l}\text { Coliformes totais foi detectado em } 50 \% \text { das amostras, todavia, nenhuma } \\
\text { amostra apresentou a presença de coliformes termotolerantes. Não foi } \\
\text { observado crescimento de bolores e leveduras nas amostras avaliadas }{ }^{2} \text {. }\end{array}$ \\
\hline Barcelos et al. (2017) & Ji - Paraná - RO & $\begin{array}{l}\mathrm{n} .: 16 \\
\text { Polpa de fruta (açaí) }\end{array}$ & $\begin{array}{l}\text { - Coliformes totais } \\
\text { - Bactérias aeróbias mesófilas* } \\
\text { - Listeria monocytogenes }\end{array}$ & $\begin{array}{l}\text { Constatou-se a presença de coliformes totais em todas as amostras, sendo } \\
\text { que } 68,75 \% \text { acima de } 10^{2} \mathrm{NMP} \cdot \mathrm{g}^{-1} \text {. Na enumeração de bactérias aeróbia } \\
\text { mesófilas verificou-se que } 25 \% \text { apresentaram contaminação }>10^{6} \text { UFC. } \mathrm{g}^{-1} \text {. } \\
\text { Ausência de L. monocytogenes. }\end{array}$ \\
\hline Coutinho et al. (2017) & Minas Gerais e Pará & $\begin{array}{l}\text { n.: } 30 \\
\text { Polpa de fruta (açaí) }\end{array}$ & $\begin{array}{l}\text { - Escherichia coli* } \\
\text { - Salmonella } \text { sp. } \\
\text { - Bolores e leveduras } \\
\text { - Bactérias aeróbias mesófilas* } \\
\text { - Staphylococcus aureus* }\end{array}$ & 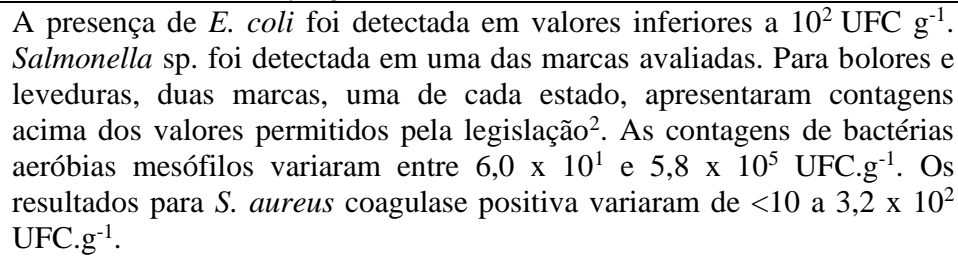 \\
\hline Feitosa et al. (2017) & Picos - PI & $\begin{array}{l}\text { n.: } 6 \\
\text { Polpas de frutas } \\
\text { (acerola e tamarindo) }\end{array}$ & $\begin{array}{l}\text { - Coliformes termotolerantes } \\
\text { - Salmonella sp. }\end{array}$ & $\begin{array}{l}\text { Todas as amostras apresentaram-se em conformidade com os limites } \\
\text { estabelecidos pela legislação }{ }^{1} \text {. }\end{array}$ \\
\hline Muniz et al. (2017) & Sudoeste da Bahia & $\begin{array}{l}\text { n.: } 27 \\
\text { Polpas } \quad \text { de } \quad \text { frutas }\end{array}$ & $\begin{array}{l}\text { - Coliformes totais* } \\
\text { - Escherichia coli }\end{array}$ & As amostras não apresentaram crescimento de coliformes totais e $E$. coli. \\
\hline
\end{tabular}




\begin{tabular}{|c|c|c|c|c|}
\hline & & (acerola, cajá e goiaba) & & \\
\hline Santos et al. (2017) & Guaraí - TO & $\begin{array}{l}\text { n.:15 } \\
\text { Polpa de fruta } \\
\text { (cupuaçu) }\end{array}$ & $\begin{array}{l}\text { - Coliformes totais e } \\
\text { termotolerantes } \\
\text { - Escherichia coli }\end{array}$ & $\begin{array}{l}\text { Apenas uma amostra apresentou crescimento coliformes totais }(>1100 \\
\left.\text { NMP.g }{ }^{-1}\right) \text {, todavia esta apresentou ausência de coliformes termotolerantes } \\
\text { e E. coli, ou seja, apresentou-se em conformidade com a legislação }{ }^{1} \text {. }\end{array}$ \\
\hline Sousa et al. (2017) & Mossoró - RN & $\begin{array}{l}\text { n.:12 } \\
\text { Polpas de frutas (umbu- } \\
\text { cajá e cajá) }\end{array}$ & $\begin{array}{l}\text { - Coliformes totais } \\
\text { - Bolores e leveduras } \\
\text { - Bactérias aeróbias mesófilas }\end{array}$ & $\begin{array}{l}\text { As enumerações de coliformes totais variaram entre }<3,0 \text { e } 9,3 \mathrm{NMP} \cdot \mathrm{g}^{-1} \text {. } \\
\text { Somente uma amostra apresentou valores acima do limite permitido pela } \\
\text { legislação para bolores e leveduras. As enumerações de bactérias aeróbias } \\
\text { mesófilas variaram entre } 1,69 \log \text { e } 3,73 \log \text { UFC. } \mathrm{g}^{-1} \text {. }\end{array}$ \\
\hline Almico et al. (2018) & Aracaju - SE & $\begin{array}{l}\text { n.: } 30 \\
\text { Polpa de fruta (açaí) }\end{array}$ & $\begin{array}{l}\text { - Coliformes totais e } \\
\text { termotolerantes } \\
\text { - Salmonella sp. } \\
\text { - Bolores e leveduras }\end{array}$ & $\begin{array}{l}\text { A presença de coliformes totais foi detectada apenas em uma das amostras } \\
\text { com média de } 2,3 \mathrm{NMP} \cdot \mathrm{g}^{-1} \text {. Coliformes termotolerantes e Salmonella sp. } \\
\text { não foram detectados em nenhuma das amostras avaliadas, estando em } \\
\text { conformidade com a lesgialação } 0^{1,2} \text {. Apenas uma das amostras avaliadas } \\
\text { apresentou-se fora do padrão exigido pela legislação } 0^{2} \text { para bolores e } \\
\text { leveduras. }\end{array}$ \\
\hline Araújo et al. (2018) & Salgueiro - PE & $\begin{array}{l}\text { n.:15 } \\
\text { Polpas de frutas } \\
\text { (abacaxi, caju, cajá, } \\
\text { manga e maracujá) }\end{array}$ & - Bolores e leveduras & $\begin{array}{l}\text { Todas as amostras apresentaram-se conforme com os } \text { padrões } \\
\text { estabelecidos pela legislação }{ }^{2} \text { para bolores e leveduras. }\end{array}$ \\
\hline Jesus et al. (2018) & Macapá - AP & $\begin{array}{l}\text { n.:10 } \\
\text { Polpa de fruta (açaí) }\end{array}$ & $\begin{array}{l}\text { - Coliformes termotolerantes } \\
\text { - Salmonella sp. }\end{array}$ & 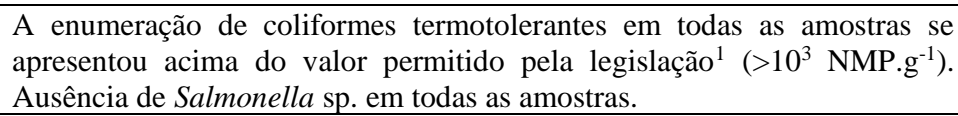 \\
\hline Marinho et al. (2018) & São Luis - MA & $\begin{array}{l}\text { n.:10 } \\
\text { Polpa de fruta (açaí) }\end{array}$ & $\begin{array}{l}\text { - Coliformes totais e } \\
\text { termotolerantes } \\
\text { - Escherichia coli } \\
\text { - Salmonella sp. } \\
\text { - Bolores e leveduras }\end{array}$ & $\begin{array}{l}\text { Todas as amostras apresentaram contagens de } 2.400 \text { UFC. }{ }^{-1} \text { para } \\
\text { coliformes totais. Em adição, todas estavam fora do padrão para } \\
\text { coliformes termotolerantes e bolores e leveduras estabelecidos pela } \\
\text { legislação }{ }^{1,2} \text {. Além disso, duas amostras apresentaram presença de E. coli. } \\
\text { Todas as amostras apresentaram ausência de Salmonella sp. }\end{array}$ \\
\hline Santos \& Romão (2018) & Ji-Paraná - RO & $\begin{array}{l}\text { n.15 } \\
\text { Polpa de fruta (açaí) }\end{array}$ & $\begin{array}{l}\text { - Coliformes totais } \\
\text { termotolerantes } \\
\text { - Salmonella sp. } \\
\text { - Bolores e leveduras }\end{array}$ & $\begin{array}{l}\text { Três amostras apresentaram valores acima de } 10^{3} \mathrm{NMP} \cdot \mathrm{g}^{-1} \text { para coliformes } \\
\text { totais e termotolerantes. Portanto, } 60 \% \text { das amostras não estavam em } \\
\text { conformidade para o limite de coliformes termotolerantes exigidos pela } \\
\text { legislação }{ }^{1} \text {. Apenas uma amostra apresentou valores de bolores e leveduras } \\
\text { em não conformidade com a legislação }{ }^{2} \text {. Salmonella } \text { sp. não foi detectada } \\
\text { nas amostras avaliadas. }\end{array}$ \\
\hline Ferreira et al. (2019) & Vitória da Conquista - BA & $\begin{array}{l}\text { n.:27 } \\
\text { Polpa de fruta (açaí) }\end{array}$ & $\begin{array}{l}\text { - Coliformes totais } \\
\text { termotolerantes* } \\
\text { - Salmonella } \mathrm{sp} \text {. }\end{array}$ & $\begin{array}{l}\text { A enumeração de coliformes totais variou entre }\left\langle 1,0 \times 10^{2} \text { a } 1,0 \times 10^{4}\right. \\
\text { NMP. } \mathrm{g}^{-1} \text {. Todas as amostras apresentaram contagens de coliformes } \\
\text { termotolerantes abaixo do limite permitido pela legislação }{ }^{1} \text {. Ausência de } \\
\text { Salmonella sp. em todas as amostras. }\end{array}$ \\
\hline Lanz et al. (2019) & Rio Grande do Sul - RS & $\begin{array}{l}\text { n.:12 } \\
\text { Polpas de frutas (uva e } \\
\text { acerola) }\end{array}$ & $\begin{array}{l}\text { - Bactérias aeróbias mesófilas } \\
\text { - Bolores e leveduras }\end{array}$ & $\begin{array}{l}\text { Todas as amostras apresentaram contagens de bolores e leveduras com } \\
\text { valores acima do permitido pela legislação }{ }^{2} \text {. As contagens de bactérias } \\
\text { aeróbias mesófilas variaram entre } 2,6 \times 10^{2} \text { e } 9,4 \times 10^{2} \text { UFC. } \mathrm{g}^{-1} \text {. }\end{array}$ \\
\hline Abadio et al. (2020) & Araguari - MG & $\begin{array}{l}\mathrm{n} .: 10 \\
\text { Polpa de fruta (açaí) }\end{array}$ & $\begin{array}{l}\text { - Coliformes totais e } \\
\text { termotolerantes } \\
\text { - Escherichia coli } \\
\text { - Bolores e leveduras }\end{array}$ & 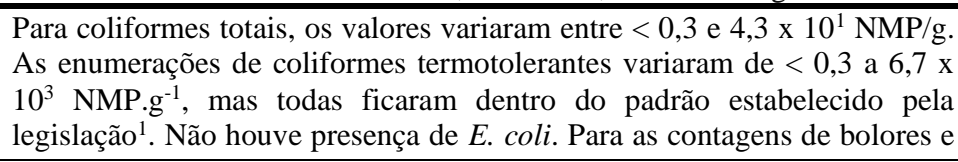 \\
\hline
\end{tabular}




\begin{tabular}{|c|c|c|c|c|}
\hline & & & & leveduras, três amostras estavam em desacordo com a legislação ${ }^{2}$. \\
\hline Aires et al. (2020) & Igarapé-Miri - PA & $\begin{array}{l}\text { n.: } 35 \\
\text { Polpa de fruta (açaí) }\end{array}$ & $\begin{array}{l}\text { - Coliformes termotolerantes } \\
\text { - Salmonella sp. } \\
\text { - Bolores e leveduras } \\
\text { - Bactérias aeróbias mesófilas }\end{array}$ & $\begin{array}{l}\text { Todas as amostras estavam em conformidade com legislação }{ }^{4} \text { para } \\
\text { coliformes termotolerantes e bolores e leveduras. A pesquisa de } \\
\text { Salmonella sp., mostrou ausência em todas as amostras. As enumerações } \\
\text { de bactérias aeróbias mesófilas variaram entre } 1,0 \times 10^{2} \text { e } 8,1 \times 10^{3} \text { UFC.g- } \\
1 \text {. }\end{array}$ \\
\hline Amorim et al. (2020) & São Luís - MA & $\begin{array}{l}\text { n.: } 08 \\
\text { Polpas de frutas (bacuri } \\
\text { e cupuaçu) }\end{array}$ & $\begin{array}{l}\text { - Bolores e leveduras } \\
\text { - Salmonella sp. } \\
\text { - Staphylococcus aureus }\end{array}$ & $\begin{array}{l}\text { Todas as amostras apresentaram contagens acima do valor permitido pela } \\
\text { legislação para contagem de bolores e leveduras. Duas amostras } \\
\text { apresentaram presença de Salmonella sp.. As contagens de S. aureus } \\
\text { variaram de } 1,1 \times 10^{4} \text { a } 1,2 \times 10^{8} \text { UFC. }^{-1} \text {. }\end{array}$ \\
\hline Andrade et al. (2020) & Teresina - PI & $\begin{array}{l}\text { n. } 4 \\
\text { Polpas de fruta (açaí) }\end{array}$ & $\begin{array}{l}\text { - Coliformes totais } \\
\text { termotolerantes } \\
\text { - Salmonella } \mathrm{sp} \text {. }\end{array}$ & $\begin{array}{l}\text { Todas as amostras mostraram-se em acordo com o padrão estabelecido } \\
\text { pela legislação }{ }^{1} \text {. Observou-se ausência de coliformes totais, coliformes } \\
\text { termotolerantes e Salmonella sp. em todas as amostras. }\end{array}$ \\
\hline Carvalho et al. (2020) & Machado - MG & $\begin{array}{l}\text { n.: } 10 \\
\text { Polpa de fruta } \\
\text { (maracujá) }\end{array}$ & $\begin{array}{l}\text { - Coliformes totais } \\
\text { - Salmonella sp. } \\
\text { - Bolores e leveduras }\end{array}$ & $\begin{array}{l}\text { Todas as amostras apresentaram valores de coliformes totais }<3,0 \mathrm{NMP.g} \\
1 \text {. Além disso, todas as amostras apresentaram valores inferiores ao limite } \\
\text { estabelecido pela legislação }{ }^{1,3} \text { para bolores e leveduras. Ausência de } \\
\text { Salmonella sp. em todas as amostras. }\end{array}$ \\
\hline Costa et al. (2020) & Manaus - AM & $\begin{array}{l}\text { n.: } 5 \\
\text { Polpa de fruta (açaí) }\end{array}$ & $\begin{array}{l}\text { - Coliformes totais } \\
\text { termotolerantes }\end{array}$ & $\begin{array}{l}\text { Todas amostras apresentaram presença de coliformes totais e somente uma } \\
\text { das amostras estava em acordo com o limite estabelecido pela legislação }{ }^{1} \\
\text { para coliformes termotolerantes. }\end{array}$ \\
\hline Ferreira et al. (2020) & Belém - PA & $\begin{array}{l}\text { n.:15 } \\
\text { Polpa de fruta (açaí) }\end{array}$ & $\begin{array}{l}\text { - Coliformes totais } \\
\text { termotolerantes } \\
\text { - Salmonella sp. } \\
\text { - Bactérias aeróbias mesófilas }\end{array}$ & $\begin{array}{l}\text { As enumerações de coliformes totais e termotolerantes variaram entre }<3,0 \\
\text { a }>1.100 \text { NMP.g }{ }^{-1} \text {, estando oito amostras com contagens acima do } \\
\text { permitido pela legislação para coliformes termotolerantes. As } \\
\text { enumerações de bactérias aeróbias mesófilas variaram de } 2,1 \times 10^{2} \text { a } 3,0 \mathrm{x} \\
10^{4} \mathrm{UFC}^{-\mathrm{g}^{-1}} \text {. Ausência de Salmonella sp. em todas as amostras. }\end{array}$ \\
\hline Freitas et al. (2020) & Limoeiro do Norte - CE & $\begin{array}{l}\mathrm{n} .: 12 \\
\text { Polpas de frutas } \\
\text { (acerola, caju, cajá e } \\
\text { maracujá) }\end{array}$ & $\begin{array}{l}\text { - Coliformes totais } \\
\text { termotolerantes } \\
\text { - Salmonella sp. } \\
\text { - Bolores e leveduras }\end{array}$ & $\begin{array}{l}\text { Todas as amostras apresentavam em conformidade com os limites } \\
\text { permitidos pela legislação }{ }^{1} \text { para coliformes termotolerantes. Todavia, sete } \\
\text { amostras apresentaram-se não conforme para o limite permitido pela } \\
\text { legislação }{ }^{3} \text { de bolores e leveduras. Ausência de Salmonella sp. em todas } \\
\text { amostras. }\end{array}$ \\
\hline Oliveira et al., 2020 & Limoeiro do Norte - CE & $\begin{array}{l}\mathrm{n} .: 12 \\
\text { Polpa de fruta (abacaxi) }\end{array}$ & $\begin{array}{l}\text { - Coliformes totais } \\
\text { termotolerantes } \\
\text { - Salmonella sp. } \\
\text { - Bolores e leveduras }\end{array}$ & 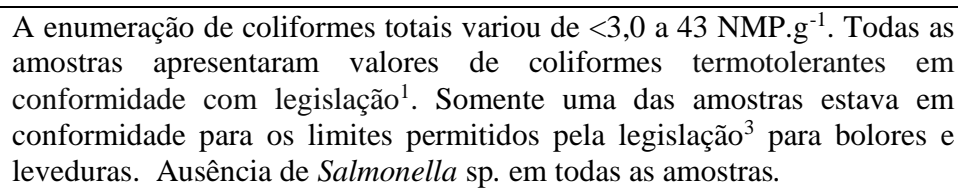 \\
\hline Santos \& Viera (2020) & João Pessoa - PB & $\begin{array}{l}\text { n.:16 } \\
\text { Polpas de frutas } \\
\text { (maracujá, mangaba, } \\
\text { caju, graviola, acerola, } \\
\text { cajá, manga, umbu-cajá } \\
\text { e uva. }\end{array}$ & $\begin{array}{l}\text { - Coliformes totais } \\
\text { termotolerantes } \\
\text { - Salmonella } \text { sp. } \\
\text { - Escherichia coli } \\
\text { - Bolores e leveduras } \\
\text { - Bactérias aeróbias mesófilas }\end{array}$ & 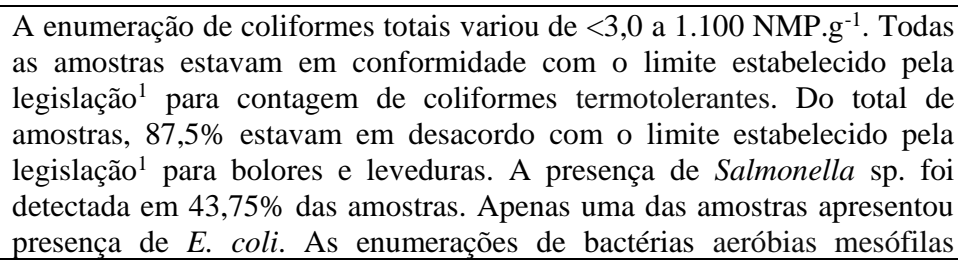 \\
\hline
\end{tabular}


Research, Society and Development, v. 10, n. 7, e17110716377, 2021

(CC BY 4.0) | ISSN 2525-3409 | DOI: http://dx.doi.org/10.33448/rsd-v10i7.16377

\begin{tabular}{|c|c|c|c|c|}
\hline & & & & variaram entre $1,0 \times 10^{3} \mathrm{e}>10^{6} \mathrm{UFC}_{\mathrm{g}} \mathrm{g}^{-1}$. \\
\hline Silva et al. (2020) & Belém do Pará - PA & $\begin{array}{l}\text { n.: } 30 \\
\text { Polpas de frutas } \\
\text { (cupuaçu, graviola, } \\
\text { manga, goiaba, acerola, } \\
\text { maracujá, caju, murici, } \\
\text { abacaxi, açaí e cacau) }\end{array}$ & $\begin{array}{l}\text { - Coliformes termotolerantes } \\
\text { - Salmonella sp. }\end{array}$ & $\begin{array}{l}\text { Do número total de amostras avaliadas, } 93,34 \% \text { encontravam-se em } \\
\text { conformidade em relação a legislação }{ }^{1} \text { para coliformes termotolerantes. } \\
\text { Além disso, Salmonella sp. não foi identificada nas amostras analisadas. }\end{array}$ \\
\hline Sousa et al. (2020) & Santarém - PA & $\begin{array}{l}\text { n.: } 9 \\
\text { Polpas de frutas } \\
\text { (acerola, cupuaçu e } \\
\text { maracujá) }\end{array}$ & $\begin{array}{l}\text { - Coliformes termotolerantes } \\
\text { - Salmonella sp. } \\
\text { - Bolores e leveduras }\end{array}$ & $\begin{array}{l}\text { Todas as amostras estavam em conformidade com a legislação, }{ }^{3} \text { para todos } \\
\text { os parâmetros avaliados. }\end{array}$ \\
\hline Souza et al. (2020) & Macapá - AM & $\begin{array}{l}\text { n. } 6 \\
\begin{array}{l}\text { Polpas de frutas } \\
\text { (abacaxi, } \\
\text { maracujá) }\end{array}\end{array}$ & $\begin{array}{l}\text { - Coliformes termotolerantes } \\
\text { - Salmonella sp. }\end{array}$ & $\begin{array}{l}\text { As enumerações de coliformes termotolerantes mostram que } 50 \% \text { das } \\
\text { amostras apresentaram valores acima do permitido pela legislação }{ }^{1} \text {. Todas } \\
\text { as amostras apresentaram ausência de Salmonella sp.. }\end{array}$ \\
\hline Torres et al. (2020) & Carajás - PA & $\begin{array}{l}\text { n.: } 20 \\
\text { Polpas de frutas } \\
\text { (abacaxi, acerola, cajá, } \\
\text { cupuaçu e goiaba) }\end{array}$ & $\begin{array}{l}\text { - Coliformes termotolerantes } \\
\text { - Salmonella sp. }\end{array}$ & Todas as amostras apresentaram-se em conformidade com a legislação ${ }^{4}$. \\
\hline
\end{tabular}

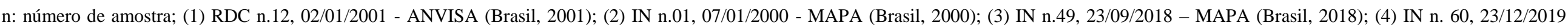
(Brasil,2019); ${ }^{(*)}$ Método de análise rápido.

Fonte: Autores. 
Do total de estudos avaliados, 14,3\% (8 estudos) realizaram somente a enumeração dos coliformes totais. Essa análise não é reconhecida como padrão microbiológico pela legislação brasileira, não existindo valor máximo permitido para esse grupo de micro-organismos para polpas de frutas (Brasil, 2000; Brasil, 2001; Brasil 2019). O grupo dos coliformes totais são bactérias pertencentes a família Enterobacteriaceae capazes de fermentar a lactose e produzir gás em temperatura de $35{ }^{\circ} \mathrm{C}$. Dentre as bactérias que são dotadas dessa capacidade metabólica, destaca-se Escherichia coli, que tem como habitat original o trato gastrointestinal de homens e animais, e bactérias não entéricas encontradas no meio ambiente, a citar as pertencentes aos seguintes gêneros: Citrobacter, Enterobacter, Klebsiella, Serratia, dentre outras (Silva et al., 2017).

Historicamente esse grupo de micro-organismos foi utilizado como indicador de níveis de contaminação fecal e, consequentemente, potencial de presença de patógenos entéricos. Todavia, como a maioria das espécies que compõem o grupo dos coliformes totais podem ser facilmente isoladas do meio ambiente, esse grupo possui limitada relevância higiênica (Forsythe, 2013). Entretanto, alguns estudos afirmam que altas contagens de coliformes totais, principalmente valores acima de 1.100 NMP.g ${ }^{-1}$, podem estar relacionadas a falhas nas boas práticas de fabricação (BPF), ineficiência de procedimentos de limpeza e sanitização do ambiente, bem como equipamentos usados durante e após o processamento dos alimentos (Farias et al., 2012; Passos et al., 2015; Santos \& Viera, 2020).

Em relação a análise de coliformes totais, 10 estudos (30,3\%) apresentaram valores de coliformes totais $>1.100$ NMP.g ${ }^{-1}$. Marinho et al. (2018), ao avaliarem polpa de açaí em São Luiz (MA), verificaram que 100\% das amostras apresentaram valores de coliformes totais $>1.100 \mathrm{NMP} \mathrm{g}^{-1}$. Em adição, Santos \& Romão (2018), também avaliaram polpa de açaí e observaram contagens acima de $1.100 \mathrm{NMP} / \mathrm{g}$ em 75\% das amostras avaliadas em Ji-Paraná (RO). Em contraste, vários estudos observaram ausência de crescimento desse grupo de micro-organismos em polpas de frutas comercializadas em diferentes estados do Brasil (Ferreira-Marçal et al., 2013; Freitas et al., 2015; Fechine Neto et al., 2016; Muniz et al, 2017; Andrade et al., 2020).

A legislação mais citada como padrão para avaliação de conformidade dos estudos analisados foi a Resolução n. 12 da Agência Nacional de Vigilância Sanitária (Brasil, 2001), que para polpas de frutas estabelece limite de $10^{2} \mathrm{NMP}_{\mathrm{g}} \mathrm{g}^{-1}$ para o grupo dos coliformes termotolerantes. Dentre os estudos avaliados, 28,6\% (16 estudos) avaliaram somente a enumeração de coliformes termotolerantes. Em contraste, 44,6\% (25 estudos) realizaram tanto a enumeração de coliformes totais quanto a enumeração de coliformes termotolerantes em suas investigações. $O$ total de 7 estudos (12,5\%) não realizaram a análise de enumeração de coliformes totais ou termotolerantes. Em resumo, do total de 41 estudos que realizaram a enumeração de coliformes termotolerantes, 31,7\% (13 estudos) apresentaram-se com pelo menos uma amostra com valores acima do limite permitido pela legislação brasileira (Brasil, 2001). Dentre os estudos analisados, os maiores percentuais de contaminação de coliformes termotolerantes foram verificados por Cohen et al. (2011) e Ferreira et al. (2020), ambos avaliaram polpa de açaí comercializada em Belém do Pará e verificaram que 100\% e 60\% das amostras analisadas, respectivamente, apresentaram contagens acima de $10^{2} \mathrm{NMP} \cdot \mathrm{g}^{-1}$.

O grupo de coliformes termotolerantes, um subgrupo dos coliformes totais, são bactérias capazes de fermentar lactose e produzir gases em temperatura de $45 \pm 0,5^{\circ} \mathrm{C}$. Esse subgrupo foi por muito tempo considerado representativo para a quantificação de enterobactérias somente de origem do trato gastrintestinal, em especial: E. coli. Todavia, atualmente sabe-se que determinadas cepas de enterobactérias não entéricas, como: Klebsiella pneumoniae e Enterobacter cloacae, são capazes de gerar resultados positivos em teste de verificação de fermentação de lactose e produção de gás de forma semelhante a testes positivos para E. coli. Assim, altas contagens de coliformes termotolerantes em polpas de fruta in natura, não pasteurizadas, podem sugerir contaminação fecal. Todavia, no caso de polpa de frutas pasteurizadas a alta incidência desse grupo está geralmente relacionada com higienização ineficiente da linha de processamento e contaminação pós processamento (Silva et al., 2017). 
A presença de E. coli em alimentos pode indicar contaminação de origem fecal e possível contaminação por outros patógenos entéricos; além disso, destaca-se que algumas linhagens de E. coli são virulentas e capazes de promover doença no homem (Verma et al., 2018). Recentemente, a enumeração de E. coli tornou-se um parâmetro microbiológico na nova legislação brasileira que estabelece padrões microbiológicos (Brasil, 2019). Contudo, nas legislações anteriormente vigentes, utilizadas como padrão na maioria dos estudos avaliados nesta revisão, a enumeração ou pesquisa de E. coli não era considerada como padrão microbiológico (Brasil, 2000; Brasil, 2001). Assim, o painel de estudos analisados na presente revisão, demonstrou que mesmo quando a enumeração ou pesquisa de E. coli não era considerada um padrão microbiológico exigido pela legislação, análises microbiológicas referentes a essa bactéria foram realizadas em 16 estudos (28,6\%) acerca da qualidade microbiológica de polpas de frutas comercializadas no Brasil.

Dentre o total de estudos que realizaram a pesquisa de E. coli, 37,5\% (6 estudos) revelaram presença desse microorganismo em pelo menos uma das amostras avaliadas. Em um estudo desenvolvido por Cohen et al. (2011), que avaliou a qualidade microbiológica de polpa de açaí comercializada na cidade de Belém do Pará, verificaram que 90\% das amostras apresentavam presença de E. coli. Adicionalmente, Farias et al. (2012), verificaram uma incidência de 13,8\% de E. coli em polpas de açaí comercializadas em Pouso Alegre (MG). No nordeste do país, Santos \& Viera (2020) na cidade de João Pessoa (PB), verificaram que $16,7 \%$ das amostras de polpas de frutas avaliadas apresentaram presença de E. coli.

A ausência de Salmonella sp. em $25 \mathrm{~g}$ de polpa de fruta é um padrão microbiológico estabelecido tanto pelas legislações já revogadas, consideradas como padrão na maioria dos estudos analisados nesta revisão (Brasil, 2000; Brasil, 2001), quanto nas legislações vigentes atualmente no Brasil (Brasil, 2018; Brasil, 2019). A pesquisa de Salmonella sp. foi o segundo parâmetro microbiológico mais avaliado nos estudos analisados, sendo que 16,7\% (6 estudos) detectaram a presença deste patógeno em pelo menos uma das amostras analisadas. Dentre esses, podemos citar Souza et al. (2016) e Amorim et al. (2020), que detectaram Salmonella sp. em duas das amostras de polpas de frutas avaliadas em Juazeiro do Norte (CE) e São Luiz (MA), respectivamente.

Salmonella é um dos patógenos mais frequentemente associados às gastroenterites de origem alimentar em países industrializados. Essa bactéria causa anualmente grande impacto socioeconômico devido a despesas médicas com infecções, perda de produtividade, invalidez e, em alguns casos, a morte dos indivíduos envolvidos, bem como altos custos de recolhimento de produtos contaminados já distribuídos (Moraes et al., 2019). No Brasil, esse patógeno destaca-se como o principal agente etiológico associado a surtos de doenças de origem alimentar, sendo considerado por isso uma ameaça contínua à saúde pública (Finger et al., 2018).

A enumeração de bolores e leveduras foi o terceiro parâmetro microbiológico mais realizado entre os estudos avaliados, sendo enumerado em 58,9\% dos estudos (33). A presença de bolores e leveduras é tolerada pela legislação brasileira, todavia o limite estabelecido para amostras indicativas era na faixa $10^{3} \mathrm{UFC} \cdot \mathrm{g}^{-1}$ na legislação utilizada como padrão na maioria dos estudos discutidos nesta revisão (Brasil, 2000). Entretanto, atualmente na legislação vigente o limite foi estendido para $10^{4} \mathrm{UFC}_{\mathrm{g}} \mathrm{g}^{-1}$ (Brasil, 2019).

Do total de estudos que realizaram a análise de enumeração de bolores e leveduras, 69,7\% (23 estudos) apresentaram uma ou mais amostras com valores acima de $10^{2}$ UFC. $\mathrm{g}^{-1}$. Consequentemente, esse parâmetro microbiológico foi o que mostrou maior incidência de amostras com valores acima do limite estabelecido pela legislação. No Nordeste (Marinho et al., 2018; Silva et al., 2016; Santos \& Nascimento, 2014), no Norte (Cohen et al., 2011) e no Sul (Lanz et al., 2019) do país verificaram que $100 \%$ de amostras avaliadas apresentavam-se em desacordo com a legislação vigente no período de realização dos estudos (Brasil, 2000).

Os bolores e leveduras são considerados um grupo de micro-organismos indicadores de qualidade, estando ligeiramente relacionados com práticas inadequadas de manufatura. Neste contexto, altas contagens desse grupo de micro- 
organismos podem gerar redução de vida útil do produto, resultado da deterioração do alimento, e consequentemente, perdas econômicas significativas à cadeia produtiva. Além disso, a presença de bolores e leveduras em alimentos pode representar risco de saúde pública, tendo em vista que alguns fungos filamentosos são toxigênicos, a citar os pertencentes aos gêneros: Aspergillus, Fusarium, Claviceps e Penicillium (Marinho et al., 2018; Silva et al., 2017).

A enumeração de bactérias aeróbias mesófilas ocorreu em 17,9\% dos estudos (10 estudos), mesmo não sendo um padrão microbiológico exigido pela legislação. Entretanto, a enumeração desse grupo de micro-organismos está diretamente relacionada com as condições de qualidade de produtos, práticas de manufatura, matérias-primas utilizadas, condições de processamento, manipulação e vida útil (Silva et al., 2017). Segundo Forsythe (2013) e Jay (2005), contagens de bactérias aeróbias mesófilas acima de $10^{6} \mathrm{UFC}^{-1} \mathrm{~g}^{-1}$ sugerem que o alimento está impróprio para consumo, e ainda, expressa grande risco de causar doenças de origem alimentar. Dentre os estudos que apresentaram contagens de bactérias aeróbias mesófilas analisados nesta revisão, apenas em 20\% (2 estudos) possuía amostras com valores acima de $10^{6}$ UFC.g $^{-1}$ (Santos \& Viera, 2020; Barcelos et al., 2017).

A enumeração de Staphylococcus aureus foi observada em três estudos (5,4\%), todos realizados na região Nordeste do país (Amorim et al., 2020; Souza et al., 2016; Dantas et al., 2012). S. aureus é o segundo patógeno mais envolvido em surtos de doenças transmitidas por alimentos no Brasil (Kroning et al., 2016). A sua presença em alimentos está relacionada condições sanitárias inadequadas de processamento, principalmente quando o processamento envolve presença de manipuladores. Esse micro-organismo produz uma variedade de toxinas (enterotoxinas estafilocócica clássicas e não-clássicas) altamente resistentes ao tratamento térmico, estas são as responsáveis pela intoxicação alimentar estafilocócica, uma das mais comuns doenças transmitidas por alimentos mundialmente (Silva et al., 2017).

Segundo Silva et al. (2017), valores de S. aureus acima de $10^{6} \mathrm{UFC}^{-1} \mathrm{~g}^{-1}$ são suficientes para que haja produção de enterotoxinas no alimento. Nas amostras de polpa de bacuri e cupuaçu avaliadas por Amorim et al. (2020) em São Luís (MA), 87,5\% apresentaram-se com contagens de S. aureus acima de $10^{6} \mathrm{UFC}^{-1} \mathrm{~g}^{-1}$. Em contraste, Dantas et al. (2012) ao avaliar a qualidade microbiológica de polpas de frutas comercializadas na cidade de Campina Grande (PB), obtiveram contagens de $S$. aureus entre $<10$ a 4,6 × $10^{3} \mathrm{UFC}^{-1} \mathrm{~g}^{-1}$.

\section{Conclusão}

A análise dos resultados dos estudos descritos nesta revisão descreve a realidade da qualidade microbiológica de polpas de frutas comercializadas no Brasil na década passada. Os resultados destacam que 57,1\% dos estudos descritos neste trabalho, apresentavam pelo menos uma amostra em desacordo com um ou mais parâmetros microbiológicos estabelecidos pelos órgãos competentes no território nacional. Os altos valores de bolores e leveduras e coliformes termotolerantes, e ainda, a presença de Salmonella, revelam um cenário ineficiente acerca da responsabilidade das indústrias processadoras de alimentos e órgãos responsáveis pela normatização e fiscalização de polpas de frutas comercializadas no território brasileiro.

Adicionalmente, pontua-se que as inconformidades com os padrões microbiológicos fixados, são reflexo de uma cadeia produtiva de alimentos que perpassa por deficiências na infraestrutura, capacitação de corpo técnico e falhas no controle de qualidade. Consequentemente, faz-se necessário priorizar a importância da sincronia entre todos os setores da cadeia produtiva de alimentos. Em síntese, as boas práticas de manipulação no campo, aliadas com as boas práticas de fabricação nas linhas de produção e distribuição, devem garantir a segurança dos alimentos disponibilizados para os setores atacadistas e/ou varejistas do mercado brasileiro.

Por fim, para garantir a qualidade e segurança de polpas de frutas produzidas e comercializadas no país, as unidades processadoras de frutas devem fixar estratégias eficazes nos seguintes seguimentos: i) limpeza e sanitização de matéria-prima; ii) desinfecção de superfícies e equipamentos; iii) métodos de conservação empregados; iv) cadeia do frio; v) seleção de embalagens; e vi) armazenamento e distribuição. Desta forma, o controle de qualidade das unidades processadoras de polpa de 
frutas deve garantir que em todas as etapas do fluxograma de produção não ocorra contaminação, sobretudo, nas etapas de armazenamento e transporte.

\section{Referências}

Abadio, L. V., Silva, A. R., Balieiro, L. C. T., Oliveira, C. A., \& Carrijo M. R. M. (2020). Análises microbiológicas de polpas de açaí comercializadas na cidade de Araguari/MG. Revista Master - Ensino, Pesquisa e Extensão, 5(10), 36-42.

Aires; C. B., Gomes, P. W. P., Pelais, A. C. A., Figueiredo, E. L., \& Martins, L. H. S. (2020). Physico-chemical and microbiological evaluation of açaí pulp processed in Igarapé-Miri, PA. Scientia Plena, 16 (9), 091501.

Alegbeleye O. O., Singleton, I., \& Sant'ana, A. S. (2018). Sources and contamination routes of microbial pathogens to fresh produce during field cultivation: a review. Food Microbiology, 73, 177-208.

Almico, J. D., Ferreira, I. M., Ramos, G. D., Silva, A. M. O., \& Carvalho, M. G. (2018). Avaliação da qualidade microbiológica, físico-química e química de polpas de açaí (Euterpe oleracea Mart.) pasteurizadas congeladas comercializadas em Aracaju-SE. Revista Brasileira de Higiene e Sanidade Animal, 12(2), $156-168$.

Alvarenga, M. V., Vieira, L. J., Santos, J. A R., \& Fernandes, F. M. (2017). Análise microbiológica de polpas de frutas congeladas e industrializadas. Revista Científica da Faminas (RCFaminas), 12(3), 60-65.

Amorim, G.A., Santos, T. C., Pacheco, L. S. V., Tavares, I. M.C., \& Franco, M. (2010). Avaliação microbiológica, físico-química e sensorial de polpas de frutas comercializadas em Itapetinga-BA. Enciclopédia Biosfera, 6(11), 1-8.

Amorim, P. E.C., Araujo, J. R.G., Silva, A. P. G., Almeida, J.S., Arruda, M. O., Serra, I. M. R. S., Alves, E. U., \& Melo, P. A. F. R. (2020). Chemical and microbiological evaluations of Platonia insignis Mart and Theobroma grandiflorum Schum pulps, native fruits from Brazilian Amazon. Australian Journal of Crop Science, 14(7), 1180-1185.

Andrade, J. K. S., Ferreira, M. G. Q. L., Oliveira, E. H. S., Silva, E. A. S., Negreiros, H. A., Santos, G. M., barros, N, V. A., Cavalcante, R. M. S., Oliveira, J. M. S., Rios, M. J. B. L., Costa, C. M., Brito, M. M., \& Sousa, P. V. L. (2020). Qualidade microbiológica de polpas de açaí comercializadas em um estado do nordeste brasileiro. Brazilian Journal of Development, 6(3), 12215-12227.

Araújo, E. C. O. N., Alves, J. E. A., \& Marques, L. F. (2018). Avaliação de parâmetros de qualidade de polpas de frutas congeladas comercializadas no município de Salgueiro-PE. Revista Semiárido De Visu, 6(1), 4-11.

Arcanjo, S. R. S., Oliveira, A M. C., Oliveira, E. S., Sousa, A. C. P., Neco, S. G. N., \& Sousa, B. A. B. (2014). Qualidade microbiológica de polpas de açaí congeladas comercializadas em Imperatriz, MA. Higiene alimentar, 28 (236/237), 84-87.

Barcelos, I. B., Vallati, T. B., Almeida, F. K. V., \& Prazeres, P. F. L (2017). Qualidade Microbiológica de Polpas de Açaí comercializadas no Município de Ji - Paraná, Rondônia. UNICIÊECIAS, 21(1)21-24.

Batista A. G., Oliveira, B. D., Oliveira, M. A., Guedes, T. J., Silva, D. F., \& Pinto, N. (2013). Parâmetros de qualidade de polpas de frutas congeladas: uma abordagem para produção do agronegócio familiar no Alto Vale do Jequitinhonha. Revista Tecnologia \& Ciência Agropecuária, 7(3), 49-54.

Botelho, L. L. R., Cunha, C. C. A., \& Macedo, M. (2011). O método da revisão integrativa nos estudos organizacionais. Gestão e Sociedade, 5(11), 121-136.

Brasil. Ministério da Agricultura, Pecuária e Abastecimento. Instrução Normativa $n^{o}$ 01, de 07 de janeiro de 2000. Regulamento Técnico Geral para Fixação dos Padrões de Identidade e Qualidade para Polpa de Fruta. Diário Oficial da República Federativa do Brasil, Brasília, DF, 10 jan. 2000.

Brasil. Ministério da Saúde. Resolução no 12, de 02 de janeiro de 2001. Regulamento Técnico sobre Padrões Microbiológicos para Alimentos. Diário Oficial da República Federativa do Brasil, Brasília, DF, 10 jan. 2001.

Brasil. Ministério da Agricultura, Pecuária e Abastecimento. Instrução Normativa $n^{\circ} 49$, de 26 de setembro de 2018 . Instrução Normativa estabelece a complementação dos Padrões de Identidade e Qualidade de Suco e Polpa de Fruta. Diário Oficial da República Federativa do Brasil, Brasília, DF, 27, set. 2018.

Brasil. Ministério da Saúde. Resolução $n^{\circ}$ 60, de 23 de dezembro de 2019. Instrução Normativa estabelece as listas de padrões microbiológicos para alimentos prontos para oferta ao consumidor. Diário Oficial da República Federativa do Brasil, Brasília, DF, 26 dez. 2019.

Carvalho, G. C., Lourenço, C. L., Fortes, R. R., Brigagão, T. C, S., Nachtigall, A. N., Veiga, S. N. O. M., \& Boas, B. M. V. (2020). Avaliação da Qualidade de polpa de maracujá congeladas. Research, Society and Development, 9(10), e3539108468.

Castro, T. M. N., Zamboni, P. V., Dovadoni, S., Neto, A. C., \& Rodrigues, L. J. (2015). Parâmetros de qualidade de polpas de frutas congeladas. Revista do Instituto Adolfo Lutz, 74(4), 426-436.

Chesca, A. C., Oliveira, K. E. R., Santos, A. L. S., \& D’angelis, C. E. M. (2015). Qualidade microbiológica de polpa de acerola (Malpighia emarginata D.C.) congelada. Higiene Alimentar, 29(242/243), 135-139.

Cohen, K. O., Matta, V. M., Furtado, A. A. L., Medeiros, N. L., \& Chisté, R. C. (2011). Contaminantes microbiológicos em polpas de açaí comercializadas na cidade de Belém-PA. Revista Brasileira de Tecnologia Agroindustrial, 5(2), 524-530.

Costa, F. C. F. C., Gomes, C. F., Erazo, R. L., Carvalho, E. B.S., \& Alencar, Y. B. (2020). Análise da qualidade microbiológica de polpas de açaí comercializadas em cinco feiras livres da cidade de Manaus. Brazilian Journal of Development, 6(7), 47667-47677. 
Coutinho, R. M. P., Fontes, E. A. F., Vieira, L. M., Barros, F. A. R., Carvalho, A. F., \& Stringheta, P. C. (2017). Physicochemical and microbiological characterization and antioxidant capacity of açaí pulps marketed in the states of Minas Gerais and Pará, Brazil. Ciencia Rural, 47(1), e20151172.

Dantas, R. L.; Rocha, A. P. T., Araújo, A. S., Rodrigues, M. S. A., \& Maranhão, T. K. L. (2012). Qualidade microbiológica de polpa de frutas comercializadas na cidade de Campina Grande, PB. Revista Brasileira de Ciências Agrárias,14(2), 125-130.

Ding, T., Suo, Y., Xiang, Q., Zhao, X., Chen, S., Ye, X. Y., \& Liu, D. (2017.). Significance of viable but nonculturable Escherichia coli: induction, detection, and control. Journal of Microbiology and Biotechnology, 27(3), 417-428.

Elias, S. O, Decol, L. T., \& Tondo, E. C. (2018). Foodborne outbreaks in Brazil associated with fruits and vegetables: 2008 through 2014. Food Quality and Safety, 2, 173-181.

Escole, F. F, Melo, L. S., Alcoforado, C. L. G. C. (2014). Revisão Integrativa versus Revisão Sistemática. Revista Mineira de Enfermagem, 18(1), editorial.

Esper, A. J. F.; \& Cunha, C. J. C. A. (2015). Liderança autêntica: uma revisão integrativa. NAVUS - Revista de Gestão e Tecnologia, 5(2), 60-72.

Eto, D. K., Kano, A. M., Borges, M. T. M. R., Brugnaro, C., Antonini, S. R. C., \& Bernardi, M. R. V. (2010). Qualidade microbiológica e físico-química da polpa e mix de açaí armazenada sob congelamento. Revista Instituto Adolfo Lutz, 69(3), 304-310.

Farias, M., Oliveira, B. D., \& Costa, F. E. C. (2012). Determinação da qualidade microbiológica de polpas de açaí congeladas comercializadas na cidade de Pouso Alegre - MG. Alimentos e Nutrição, Araraquara, 23(2), 243-249.

Faria, R. A. P., Brasil, A. S., Rosa, O. O., \& Siqueira, N. M. F. P. (2016). Avaliação da qualidade microbiológica de polpas de frutas congeladas comercializadas na cidade de Cuiabá - MT. Higiene Alimentar, 30(256/257).

Fechine Neto, J. L., Calou, V. C. R., Silva, J. R, A., \& Mendes, R. C. (2016). Perfil microbiológico de amostras de polpas de frutas congeladas, comercializadas na cidade de Missão Velha-CE. Caderno de Cultura e Ciência, 15(1), 47-56.

Feitosa, R. C., Sousa, A. C. P., Teixeira, S. A., \& Medeiros, S. R. A. (2017). Avaliação da rotulagem da qualidade microbiológica e físico-química de polpas de frutas comercializadas em Picos-PI. Revista Intertox de Toxicologia, Risco Ambiental e Sociedade, 10(2), 62-72.

Ferreira, C. H. B., Espinheira, M. J. C. L., David, I. R., Duarte, S. F. P., Sousa, B. R., \& Souza, F. M. (2019). Quality acai marketed pulp microbiological in municipality of Victory Conquer BA. International Journal of Advanced Engineering Research and Science, 6(6), 712-719.

Ferreira, J. F., Ferreira, W. L., \& Freitas, A. E. S. (2020). Perfil microbiológico de polpas de açaí in natura, pasteurizadas e congeladas, comercializadas na região metropolitana de Belém do Pará. Brazilian Journal of Development, 6(6), 41450-41457.

Ferreira-Marçal, P. H., Dias-Souza, M. V., Villela, E. G., Luz, L. M., Pereira, M. K., Vale, C. H. B. D., \& Rabelo, F. L. A. (2013). Qualidade físico-química, microbiológica e microscópica de polpas de frutas congeladas comercializadas no município de Governador Valadares, MG. Nov@: Revista Científica, 2(2), $1-10$.

Finger, J., Baroni, W., Maffei, D. F., Bastos, D., \& Pinto, U. M. (2019). Overview of Foodborne Disease Outbreaks in Brazil from 2000 to 2018. Foods (Basel, Switzerland), 8(10), 434

Forsythe, S. J. (2013). Microbiologia da segurança dos alimentos. (2a ed.), Artmed.

Freitas, B., Bento, F.S., Santos, F. Q., Figueiredo, M., América, P., \& Marçal, P. (2015). Características físico-químicas, bromatológicas, microbiológicas e microscópicas de polpas de açaí (Euterpe oleraceae) congeladas do tipo b. Journal of Applied Pharmaceutical Sciences, 2(2), 2-13.

Freitas, R. V. da S., Souza, P. A. de, Soares, D. J., Reges, S. C. N., Oliveira, Z. L. de, \& Costa, F. B. da. (2020). Perfil da qualidade de polpas de frutas comercializadas no Município de Limoeiro do Norte, Estado do Ceará, Brasil. Research, Society and Development, 9(8), e806986166.

Jay, J. M. (2005). Microbiologia de Alimentos. (6a ed.), Artmed.

Jesus, L. M., Brito, R. S., Nascimento, S. F., Vieira, T. R., Soares, N. R. M., \& Silva-Junior, A. C. S. (2018). Avaliação microbiológica do açaí comercializado no bairro Santa Rita, Macapá- -Amapá. Revista Arquivos Científicos (IMMES), 1 (2), 21-27.

Jones, L. C., \& Lemes, R. M. L. (2014). Análise microbiológica de polpas de açaí comercializadas em uma cidade do sul de Minas Gerais. Revista da Universidade Vale do Rio Verde, 12(2), 601-608.

Kroning, I. S., Iglesias, M. A., Sehn, C. P., Valente Gandra, T. K., Mata, M. M., \& Silva, W. P. (2016). Staphylococcus aureus isolated from handmade sweets: Biofilm formation, enterotoxigenicity and antimicrobial resistance. Food microbiology, 58, 105-111.

Lanz, C., Nachtiga, L., \& Severo, J. (2019). Parâmetros de qualidade de polpas de uva e acerola congeladas. Revista de Ciência e Inovação do IF Farroupilha, 4(1), 94-105.

Macena, T. N. Da S., Fortuna, J. L.; Souza, B. Do A. E.; \& Lopes, E. S. (2010). Análise da qualidade microbiológica e higiênico-sanitária de polpas de frutas comercializadas em supermercados do município de Teixeira de Freitas, BA. Revista Mosaicum, 6(12), 2010.

Machado, S. S., Tavares, J. T.Q., Cardoso, R. L., Machado, C. S., \& Souza, K. E. P. (2007). Caracterização de polpas de frutas tropicais congeladas comercializadas no recôncavo baiano. Revista Ciência Agronômica, 38(2) 158-163.

Marinho, O. S. C., Moura, A. R. N., Rabelo, H. P. S. M., Silva, G. M., \& Furtado, J. G, C. (2018). Condições microbiológicas de polpas congeladas de açaí comercializadas em mercados públicos de São Luís - MA. Journal of Health Connections, 2(1), 44-59.

Moher, D., Shamseer, L., Clarke, M., Ghersi, D., Liberati, A., Petticrew, M., Shekelle, P. Stewart, L. A. \& Prisma-P Group (2009). Preferred reporting items for systematic review and meta-analysis protocols (PRISMA-P) 2015 statement. PLOS Medicine, 6(7), e1000097. 
Moraes, J. O., Cruz, E. A., Pinheiro, Í., Oliveira, T., Alvarenga, V., Sant'Ana, A. S., \& Magnani, M. (2019). An ordinal logistic regression approach to predict the variability on biofilm formation stages by five Salmonella enterica strains on polypropylene and glass surfaces as affected by $\mathrm{pH}$, temperature and $\mathrm{NaCl}$. Food microbiology, 83, 95-103.

Muniz, C. M., Reis, R. B. S., \& Vieira, V. F. (2017). Coliformes totais e Escherichia coli em polpas de frutas comercializadas no Sudoeste da Bahia. Id onLine Revista de Psicicologia, 11(35).

Nascimento, A. R., Martins, A. G. L. A., Aragão, N. E., Serra, J. L., Medez Filho, N. E., Pinheiro, R. T., Souza, F. T. N., \& Silva, D. S. V. (2013). Ocorrência e distribuição de enterobactéerias em polpas de frutas não pasteurizadas e pasteurizadas, congeladas e comercializadas na cidade de São Luís, MA. Higiene Alimentar, 27(226/227), 120-124.

Oliveira, A. T. C. de, Silva, F. T. de S., Mendes, L. G., Monte, A. L. de S, \& Cavalcante, A. B. D. (2020). Perfil físico-químico e microbiológico de polpas de frutas congelada comercializadas em Limoeiro do Norte (Ce). Research, Society and Development, 9(11), e549119473.

Paiva, M. R. F., Parente, J. R. F., Brandão, I. R., \& Queiroz, A. H. B. (2016). Metodologias Ativas de Ensino aprendizagem: Revisão Integrativa. SANARE, Sobral, 5(2), 145-153.

Passos, L. P., Miranda, A. L. S., Marques, D. R. P., \& Oliveira, I. R. N. (2015). Aspectos microbiológicos de cenouras minimamente processadas e armazenadas em diferentes embalagens sob-refrigeração. The Journal of Engineering and Exact Sciences, 3(6), 0829-0834.

Sant'anna, P. B.; Franco, B. D.G., \& Maffei, D. F. (2020). Microbiological safety of ready-to-eat minimally processed vegetables in Brazil: an overview. Journal of the Science of Food and Agriculture, 100(13).

Santos, C. A. A., Coelho, A.F.S., \& Carreiro, S.C. (2008). Avaliação microbiológica de polpas de frutas congeladas. Ciência e Tecnologia de Alimentos, 28(40), 913-915.

Santos, D. P., \& Barros, B. C. V. (2012). Perfil higiênico sanitário de polpas de frutas produzidas em comunidade rural e oferecidas à alimentação escolar. Revista Brasileira de Tecnologia Agroindustrial, 6(2), 747-756.

Santos, W. C., \& Nascimento, A. R. (2014). Caracterização microbiológica de polpas de quatro frutas regionais comercializadas nas feiras de São Luís/MA. Cadernos de Pesquisa, 21(special number), 1-7.

Santos, R. F. S, Horita, H, Prado, J. C. S., Braga, A. V. U., \& Morelli, S. A. (2015). Avaliação da qualidade microbiológica de sucos naturais, frutas e polpas congeladas comercializados na cidade de Campinas, SP. Higiene alimentar, 29 (248/249), 184-188.

Santos, B. A., Campofiorito, M. C., Pinto, J. L., Penteado, S. H., Fonseca, F. L., \& Gehrke, F. S. (2016a) Análise microbiológica de polpas de açaí comercializadas na cidade de São Paulo. Revista Brasileira de Análises Clinicas, 48(1), 53-7a.

Santos, E. H. F., Figueiredo Neto, A., \& Donzeli, V. P. (2016b). Aspectos físico-químicos e microbiológicos de polpas de frutas comercializadas em Petrolina (PE) e Juazeiro (BA). Brazilian Journal of Food Technology, 19, e2015089b.

Santos, W. M. S, Cardoso, T. S., Lopes, J. G, Andrade, S. P, \& Guimarães, A. P. M. (2017). Avaliação da qualidade microbiológica de polpas de cupuaçu (Theobroma grandiflorum schum) comercializadas no município de Guaraí/TO. Scire Salutis, 7(2), 20-31.

Santos, F. N., \& Romão, N. F. (2018). Avaliação microbiológica e parasitológica de polpas de açaí comercializadas na cidade de Ji-Paraná - RO. Revista de Saúde e Biologia, 12(2) 27-32.

Santos, R. E., \& Viera, P. P. F. (2020). Avaliação da qualidade microbiológica de polpas de frutas artesanais produzidas e comercializadas nos mercados públicos do município de João Pessoa. Brazilian Journal of Development, 6(9), 72847 - 72857.

Silva, M. E. S., Andrade, O. M. M., Novais, T. M.G., \& Mocelin, A. F. B., Figueiredo, P. M. S. (2013). Qualidade microbiológica da polpa de cupuaçu comercializada nas principais feiras de São Luís, MA. Higiene Alimentar, 27(224/225), 129-134.

Silva, L. M. R., Teixeira de Figueiredo, E. A., Silva Ricardo, N. M., Pinto Vieira, I. G., Wilane de Figueiredo, R., Brasil, I. M., \& Gomes, C. L. (2014). Quantification of bioactive compounds in pulps and by-products of tropical fruits from Brazil. Food chemistry, 143, $398-404$.

Silva, A. N., Santos, A. M. G., Cortz, E. A., \& Cordeiro, B. C. (2015). Limites e possibilidades do ensino à distância (EaD) na educação permanente em saúde: revisão integrativa. Ciência \& Saúde Coletiva, 20(4),1099-1107.

Silva, C. E. F, Moura, E. M. O, Souza, J. E. A, \& Abud, A. K. S. (2015). Quality control of tropical fruit pulp in Brazil. Chemical Engineering Transactions, 44, 193-198.

Silva, C. E. F.; Moura, E. M. O, Andrade, F. P, Gois, G. N. S. B, Silva, I. C. C, Silva, L. M. O, Souza, J. E. A, \& Abud, A. K. S. (2016a). Importância da monitoração dos padrões de identidade e qualidade na indústria de polpa de fruta. Journal of Bioenergy and Food Science, 3(1), 17-27.

Silva, G. S., Coutinho, T. C., \& Soares, L. S. (2016b). Qualidade de polpas de frutas congeladas comercializadas na cidade de Salvador-BA. Higiene Alimentar, 30(258/259), 78-82.

Silva, C. E. F., \& Abud, A. K. S. (2017) Tropical fruit pulps: processing, product standardization and main control parameters for quality assurance. Brazilian Archives of Biology and Technology, 60, e160209.

Silva, N., Junqueira, V. C. A., Silveira, N. F. De A., Taniwaki, M. H., Gomes, A.R., \& Okazaki, M. M. (2017). Manual de Métodos de Análise Microbiológica de Alimentos e água. 5. ed. São Paulo: Brucher.

Silva, D. D. B., Martins, V. S., Pereira, J. M. C., Brasil, L.S. N. S., \& Silva, S. M. R. (2020). Análise microbiológica de polpas de frutas industrializadas comercializadas em supermercado em Belém do Pará. Revista Univap, 26(50), 36-46. 
Research, Society and Development, v. 10, n. 7, e17110716377, 2021

(CC BY 4.0) | ISSN 2525-3409 | DOI: http://dx.doi.org/10.33448/rsd-v10i7.16377

Souza, M. T., Silva, M. D., \& Carvalho, R. (2010). Revisão integrativa: o que é e como fazer. Einstein, 8 (1), 102-106.

Souza, G. C., Carneiro, J. G., \& Gonsalves, H. R. O. (2011). Qualidade microbiológica de polpas de frutas congeladas produzidas no município de Russas CE. Revista Agropecuária Científica no Semi-árido, 7(3), 01-05.

Souza, J. C. C. O., Macedo, R. O., Leandro, L. M. G., Almeida, B. J., \& Fonseca, F. L. A. (2016). Avaliação Microbiológica de polpas de frutas comercializadas na cidade de Juazeiro do Norte - CE. Higiene Alimentar, 30(254/255), 123-127.

Sousa, A. S., Soares, K. M.P., Góis, V. A., \& Freire, B. C. F. (2017). Qualidade microbiológica e físico-química de polpas de umbu-cajá e cajá comercializadas em Mossoró, RN. Higiene Alimentar, 31(272/273), 42-46.

Sousa, Y. A., Borges, M. A., Viana, A. F. S., Dias, A. L., Sousa, J. J. V., Silva, B. A., Silva, S. K. R., \& Aguiar, F. S. (2020). Avaliação físico-química e microbiológica de polpas de frutas congeladas comercializadas em Santarém - PA. Brazilian Journal of Food Technology, 23(1), 1-10.

Souza, A. C. F., Souza, J. F., \& Mendes, I. G. (2020). Avaliação microbiológica de polpas congeladas de frutas comercializadas em feiras públicas da cidade de Macapá, Amapá. Research, Society and Development, 9(2), 01-10.

Teixeira, L. F., Santos, E., Santana, R., Miranda, A., Neres, C. J., \& Júnior, N. M. (2016). Análise microbiológica de polpa congelada de manga de diferentes marcas comercializadas em Vitória da Conquista - BA. Revista de Inovação, Tecnologia e Ciências (RITEC), 2(2), 168-172.

Torres, L. C. P., Moura, R.C., Aguiar, R. O., Santos, D. B., Santos, M. A. A., Martins, L.H. S., Bernardino, P. D. L. S., \& Silva, P. A. (2020). Avaliação da qualidade de polpas de frutas congeladas comercializadas na Região de Carajás - PA. Research, Society and Development, 9(10), e7149108779.

Truchado, P., \& Allende, A. (2020). La implicación de las frutas y hortalizas em la toxiinfeciones alimentarias y la relevancia del estado fisológico de las bactérias. ARBOR Ciencia Pensamiento y cultura, 196(795), a541.

Urbano, G. R., Maziero, P. P., Kato, T., \& Pedrão, M. R. (2012). Avaliação de parâmetros de qualidade de polpas de acerolas congeladas comercializadas em Londrina - PR. Revista Brasileira de Pesquisa em Alimentos, 3(1), 28-31.

Verma, P.; Sahanan, V, V.; \& Singh, A. P. (2018). Phenotypic and virulence traits of Escherichia coli and Salmonella strains isolated from vegetables and fruits from India. Journal of Applied Microbiology, 125, 270-281. 